\title{
Investigaciones arqueológicas en el cerro con muros concéntricos de Cerro Colorado, Valle de Huaura, Perú
}

\author{
Pieter D. van Dalen Luna
}

\begin{abstract}
Resumen
En el presente artículo se presenta los resultados de las investigaciones con excavaciones realizadas en el sector A de Cerro Colorado en el valle de Huaura. Este sector correspondiente a un cerro con muros concéntricos, ha sido muy descrito en los últimos años, aunque es la primera vez que se han realizado investigaciones intensivas que nos permiten conocer con mayor detalle sobre la arquitectura conformante y su funcionalidad. Los resultados de las investigaciones revelaron el hallazgo de materiales y contextos rituales y domésticos, por lo que planteamos que este sitio cumplió una función ritual, relacionado con el culto al mar (Mamacocha y Urpiwachak).
\end{abstract}

Palabras claves: Perú, Huacho, cultura Chancay, culto al mar, ofrenda, área ceremonial.

\section{Abstract \\ ARCHAEOLOGICAL INVESTIGATIONS IN THE HILL WITH CONCENTRIC WALLS FROM CERRO COLORADO, HUAURA VALLEY, PERU}

This article presents the results of the studies that included excavations carried out in sector $A$ of the Cerro Colorado in the Huaura Valley. This sector corresponds to a hill with concentric walls, and has been described by various scholars in recent years. Nevertheless, it is the first time that intensive research has been carried out that allows us to know in greater detail about the conformant architecture and its functionality. The results of the investigations revealed the finding of ritual and domestic materials and contexts, and it is proposed that this site fulfilled a ritual function, related to the cult of the sea (Mama-cocha and Urpiwachak).

Keywords: Perú, Huacho, Chancay culture, cult of the sea, offering, ceremonial area.

Pieter D. van Dalen Luna - Universidad Nacional Mayor de San Marcos / Colegio de Arqueólogos del Perú, pvandalen2@hotmail.com, https://orcid.org/0000-0002-2498-9242 


\section{Introducción}

El año 2015 se realizó el Proyecto de Investigación Arqueológica Cerro Colorado, en el cual se realizaron excavaciones en área en los sectores A y B, distribuyéndose en diferentes áreas del complejo arqueológico. Para el caso del sector A (cerro con muros concéntricos) se realizó la excavación de 11 unidades de diferentes dimensiones, con el objetivo de determinar las características de los muros perimétricos y si es que presentan infraestructura asociada; así como tener una aproximación a la funcionalidad del sitio.

La inquietud por investigar estos sitios de la cultura Chancay se inició a finales de la pasada década y se intensificaron durante mis labores como co-director del Dr. Andrzej Krzanowski, en los trabajos desarrollados en los valles de Chancay y Huaura, como las excavaciones en los sitios de Pasamayo. Por ello, considero importante presentar en esta edición de homenaje a uno de los más grandes arqueólogos peruanistas, el primer arqueólogo polaco en realizar investigaciones en el Perú, el Dr. Krzanowski, los resultados de estas investigaciones que realizamos en el sector A del complejo arqueológico de Cerro Colorado, presentando detalladamente el proceso de excavación, los contextos y datos recuperados, para posteriormente plantear aspectos relacionados a su funcionalidad.

\section{La cultura chancay}

La cultura Chancay es una de las formaciones socio-políticas del Periodo Intermedio Tardío Andino (1000-1470 d.C.) que se desarrolló en la Costa Central Peruana, específicamente entre los valles de Chancay y Huaura. Su desarrolló cultural se inició en el valle de Chancay, extendiéndose luego hacia el valle de Huaura, para llegar al momento de la invasión incaica a establecerse entre el valle de Supe por el norte y hasta la margen norte del río Chillón por el sur. Hacia el año 1470 d.C. fueron dominados por el Tawantinsuyu, pasando a formar parte del Chinchaysuyu, periodo en el cual la cultura Chancay siguió desarrollándose bajo la dominación incaica, desarrollando sus manifestaciones socio culturales propias, aportando el tributo al Estado Inca y recibiendo de este en redistribución, otros productos al cual normalmente no tenían acceso. El desarrollo de la cultura Chancay se puede dividir así, en los siguientes periodos (van Dalen 2015):

1) Periodo Chancay Inicial (850 - 1000 d.c.): Corresponde al periodo de transición del Horizonte Medio representado por las culturas: Teatino, Huaura, Pativilca, entre otras, a la cultura Chancay.

2) Periodo Chancay (1000 - 1300 d.c.): Corresponde al periodo de consolidación de la cultura Chancay en el valle del mismo nombre, desarrollando características particulares. 
3) Periodo Chancay Expansivo (1300 - 1470 d.c.): Corresponde a la expansión de la cultura Chancay hacia el norte (valles de Huaura y Supe).

4) Periodo Chancay - Tawantinsuyu o Chancay - Inca (1470 - 1533 d.c.): Corresponde al periodo de desarrollo de la cultura Chancay bajo la dominación del Tawantinsuyu.

5) Periodo Chancay - Colonial Temprano (1533 - 1551 d.c.): Abarca desde la llegada de los primeros españoles al territorio de la Costa Norcentral (enero y febrero de 1533) hasta las reducciones de pueblos hispanos (Santo Domingo de Real Aucallama, San Juan Bautista de Huaral, Villa de Arnedo, San Bartolomé de Huacho, entre otros) y la desocupación de los pueblos autóctonos.

Los asentamientos de la cultura Chancay del valle Chancay-Huaral han sido clasificados según sus dimensiones, organización espacial, diferenciación de sectores, tipos arquitectónicos, ubicación y relación con otros asentamientos, en nueve tipos de asentamientos (van Dalen 2008: 121-128, 2009: 270-272, 2017: 24-26):

A) Sitios Político - Administrativos: Son asentamientos de gran tamaño, de más de 8 Hectáreas. Presentan una arquitectura muy compleja y monumental; además de una organización espacial muy compleja, con numerosos sectores bien demarcados: sectores habitacionales (con arquitectura a base de piedra canteada y argamasa); sectores administrativos con arquitectura monumental, plataformas con rampa, plataformas a desnivel, recintos de almacenamiento, entre otros rasgos (arquitectura a base de adobes). Estos asentamientos se ubican en las grandes quebradas laterales que se unen al valle Chancay (Tronconal A, Portillo, Pisquillo Chico, Quilca "A", Lauri, Macatón y Lumbra), o sobre las grandes terrazas aluviales adyacentes al valle (Cuyo y San Miguel). En el caso del valle bajo también se pueden ubicar en las grandes pampas que se ubican en los rincones del valle (Pasamayo, Pancha la Huaca, Chancayllo, Cerro Trinidad, Tronconal B o Huando). Todos estos asentamientos presentan ocupación durante los periodos Chancay e Inca y al parecer se habrían constituido como la sede de los ayllus locales de esta zona del valle, que por referencias etnohistóricas fueron posteriormente reducidos por los españoles en el pueblo de San Juan Bautista de Huaral.

B) Sitios Administrativos de mediana jerarquía: Son aquellos asentamientos de medianas dimensiones (entre 2 y 5 Hectáreas aprox.). Son sitios que presentan también una función administrativa, pero de un rango local. Presentan sectores domésticos conformados por numerosos recintos edificados a base de piedra canteada unida con argamasa. Estos sitios se ubican generalmente en las quebradas laterales al valle, en las pequeñas pampas aledañas al valle y sobre las pequeñas terrazas aluviales de los cerros aledaños. Estos sitios habrían sido centros de función secundaria, dentro de los ayllus que ocupaban esta zona del valle y habrían estado supeditados a los sitios anteriores. En esta categoría estarían los sitios de La Cruz, Platanal, Tronconal "B”, Andoma, Jecuán, Puerto Chancay, 
San Miguel, Santo Domingo, Quisque, Saume, Gallinazo, Miraflores, Quilca "B", entre otros

C). Asentamientos domésticos: Son sitios pequeños, de hasta 2 hectáreas, de función doméstico - habitacional y que mayormente se ubican en los pie de monte de los cerros del rincón del valle. Tienen una técnica constructiva muy simple, edificados a base de piedras canteadas edificados de manera mampuesta con o sin argamasa. Estos sitios están conformados por varios recintos y se habrían constituido en las viviendas de los agricultores o pescadores, donde solo se realizaban actividades domésticas y de vivienda.

D). Asentamientos aislados: Son asentamientos conformados por solo entre uno y cuatro recintos, ubicados en las alturas de los cerros o asociados a los caminos prehispánicos. Estos sitios habrían cumplido la función de tambos, o de control de los caminos, o pequeñas unidades domésticas totalmente aisladas.

E). Cementerios con arquitectura funerária: Son los cementerios de gran tamaño y que en su mayoría se encuentran asociados a los grandes sitios administrativos, ya que se ubican a poca distancia de estos. En el valle medio presentan una arquitectura funeraria conformada por plataformas a desnivel que le dan la forma de un pequeño "túmulo" edificada íntegramente a base de una torta de barro. Los entierros eran depositados en estas grandes cámaras funerarias. En el valle bajo existían grandes y complejas cámaras funerarias. Por la complejidad en los patrones funerarios observados en estos sitios, aquí se habría enterrado a los personajes que vivían en estos grandes centros administrativos. Todos estos cementerios se encuentran totalmente destruidos por la acción destructora de los huaqueros. Así tenemos los sitios de Sacachispa, Chancayllo, Lauri, Chacra y Mar, Jecuán, Cementerio de Cuyo, los cementerios de Portillo, Carrera, Santo Domingo, Miraflores B, Lumbra, Pisquillo Grande, entre otros.

F). Cementerios simples: Son los cementerios de tamaño pequeño, ubicados generalmente cerca de los sitios domésticos. No presentan arquitectura funeraria. Estos cementerios habrían servido para enterrar a la gente que vivía en los pequeños sitios domésticos.

G). Sitios Ceremoniales o adoratorios: Son los asentamientos de carácter ceremonial o religioso, ubicados por lo general en la cima de los cerros. Estos sitios cumplían una función mágica religiosa. Están conformados, en su mayoría, por una sola estructura, y en otros, asociado a estructuras arquitectónicas de almacenamiento. En Saume, en la margen izquierda del río, en el valle medio bajo se ha podido identificar numerosos adoratorios, los cuales en la actualidad presentan en la cima una cruz, como símbolo de superposición de la religión cristiana sobre la andina. La colocación de estas cruces se habría realizado a fines del siglo XVI y comienzos del siglo XVII, durante la extirpación de idolatrías. En el valle medio en las inmediaciones de Lumbra se han identificado adoratorios a considerable altura con respecto al valle. Hemos creído conveniente llamar 
a estos sitios "adoratorios" como una referencia a la función ceremonial que cumplieron para la población local o para los viajeros.

H). Instalaciones Agrícolas e hidráulicas: Son aquellos sitios constituidos por infraestructura agrícola e hidráulica. Entre estos tenemos aterrazamientos en las laderas de los cerros, donde se desarrollaba una agricultura de secano, los canales de irrigación, las áreas de tendales de productos, bocatomas.

I). Redes viales: Aquellos caminos que recorrían el valle Chancay y los que se interconectaban con la cuenca alta y valles vecinos.

Debemos señalar que existen ciertas diferencias culturales en cuanto a las manifestaciones culturales Chancay en el valle de Chancay-Huaral y en el valle de Huaura; por lo que debemos adelantar (lo que venimos preparando en un futuro artículo conjuntamente con el Dr. Alfredo Altamirano), que estas observaciones nos están llevando a plantear la existencia para mediados del Periodo Intermedio Tardío de dos áreas nucleares Chancay: Chancay del Norte o Chancay de Huacho y el Chancay del Sur o Chancay de Huaral. En Huacho (valle de Huaura) los asentamientos político - administrativos Chancay se ubican en medio del valle, conformados por edificaciones piramidales, sobre la cual se edificaron las áreas residenciales, predominando una arquitectura a base de tapiales (como es el caso del complejo de Walmay, el más extenso del valle de Huaura, con más de 50 estructuras piramidales); mientras que en el valle de Chancay - Huaral, como señalamos, los asentamientos político administrativos se ubican en los rincones del valle. Así mismo, en cuanto a la cerámica, en el valle de Huaura la cerámica de estilo Chancay coexiste con el estilo Huacho (local) y otros que persisten desde finales del Horizonte Medio; estilos que casi no aparecen en el valle de Chancay. Los patrones funerarios también presentan diferencias notables en ambos valles, presentando en el caso del valle de Chancay estructuras funerarias más profundas, de hasta siete metros, colocando al muerto al interior de fardos con falsa cabeza. Las estructuras funerarias en ambos valles presentan entre los materiales asociados a las figurinas cerámicas antropomorfas conocidas como "cuchimilcos", siendo las del valle de Chancay en estilo Negro sobre Blanco y con el extremo de la cabeza plana o ligeramente curva; mientras que los del valle de Huaura son de estilo Huacho, presentando colores negro y rojo sobre crema, presentando vestimenta y con la cabeza culminando con dos o tres puntas (gorro de tres o cuatro puntas, persistencia del Horizonte Medio). Estas diferencias culturales entre ambos valles y la caracterización del Chancay Norteño y el Chancay del Sur aún está en proceso de análisis más profundo, aunque creemos conveniente adelantarlo de manera general.

La población chancay desarrolló principalmente la agricultura y la pesca, aunque complementaban el aprovechamiento de estos recursos con la actividad ganadera, la caza de animales terrestres y marinos. La actividad más notable fue la textilería, pues los chancay fueron los mejores tejedores de los Andes prehispánicos conjuntamente con las culturas Paracas y Huari. Se trataba de una actividad 
diversificada, doméstica y con técnicas y patrones de manufactura uniformes. La cerámica representativa de esta cultura es el estilo Chancay, principalmente en sus tipos Negro sobre Blanco y Base Crema, con representaciones de múltiples elementos naturalistas.

\section{Los asentamientos chancay con muros concéntricos o murallas}

A partir de la segunda mitad del siglo pasado, se inicia en la Costa Central Peruana el desarrollo de proyectos de investigación regionales, orientados a realizar catastros arqueológicos o estudios de patrones de asentamientos en los valles medios y bajos. Como resultado de estos importantes proyectos que innovaron la visión arqueológica sobre las relaciones intersitios de la Costa Peruana, se fueron registrando y caracterizando sitios tipo ubicados mayormente en la cima de cerros y circundados por muros o murallas. Wilson al definir los sitios con murallas en el valle de Santa, los llama fortalezas o sitios amurallados (Wilson 1988). Otros autores han reportado la presencia de sitios amurallados en valles contiguos como la Fortaleza de Collique en el Chillón (Morales 1998), en el sitio de Chimú Cápac en el valle de Supe (Valkenier 1995), en el valle de Virú (Willey 1953), en los valles de Casma, Nepeña y Santa (Pozorski 1987, Proulx 1973, 1985; Wilson 1988, 1997, Ghezzi y Ruggles 2006, 2007). Hasta finales del siglo pasado, los investigadores coincidían en que los sitios de características amuralladas correspondían al Horizonte Temprano, y el hallar un sitio de estas características era un indicador de este periodo cultural.

Las investigaciones desarrolladas en las últimas dos décadas del siglo pasado en los valles de Chancay y Huaura por Andrzej Krzanowski, le permitieron identificar numerosos sitios con estas características, los cuales por su técnica constructiva y materiales culturales asociados, fueron asociados a periodos prehispánicos tardíos, especialmente a la cultura Chancay (Krzanowski 2008, 2016). Otra investigadora que en los últimos años ha investigado esta problemática en el valle de Huaura es Margaret Brown (Brown 2009, 2010, 2015, Brown, Craig y Ascencios 2011), quién define a estos sitios como fortalezas, caracterizadas por estar rodeadas en su perímetro por muros, parcial o totalmente (Brown 2010: 172).

Brown ha sistematizado las investigaciones pretéritas complementadas con las realizadas por ella y su equipo de investigación, definiendo la cantidad de sitios con estas características por valle correspondientes a este Periodo Intermedio Tardío: En el valle de Virú: 6 sitios; en Santa: 21; en Nepeña: 3; Casma: 34; Culebras: 2; Supe: 1, y Huaura: 6 . Se trata de sitios ubicados en las cumbres y rodeados por entre 1 y 5 muros de defensa, edificados con piedras canteadas. Las fortalezas de los valles de Nepeña y Santa se ubican en el valle medio y cuenca alta; mientras que las ubicadas en los valles de Culebras, Supe y Huaura se hallan en el valle bajo (Brown 2010: 172-174). Posteriormente, Brown amplió las investigaciones 
identificando otros 16 sitios fortificados de este periodo en el valle de Fortaleza y aumentando la cifra en el valle de Huaura a 21 (Brown 2011: 1685).

Con respecto a los seis sitios amurallados del Horizonte Temprano en el valle de Huaura, Brown los caracteriza por ubicarse en las cumbres, tienen muros defensivos y acceso restringido. Estos sitios son: Acaray, Cerro Colorado, Vilcashuaura, Rontoy, San Cristóbal, y Costado Sur del Río; de los cuales cuatro se ubican en el valle bajo y son visibles entre sí. Los tres sitios ubicados en la margen norte del valle bajo tienen una cumbre con anillos de tres muros concéntricos, caracterizados por estar edificados a base de piedras canteadas unidas con argamasa y relleno de rocas medianas (Brown 2010: 176-178).

Margaret Brown define, además, la reocupación de sitios amurallados en el valle de Huaura, con patrones muy similares a los descritos, aunque de datación correspondiente al Intermedio Tardío. Estos sitios son los de Cerro Colorado y Acaray, el primero conformado por tres muros concéntricos muy destruidos, y el segundo con tres cumbres cada una de entre 1 a 3 muros concéntricos de defensa, cuya técnica de construcción es mediante capas alternas de material vegetal y piedras; con relleno de piedras, basura y tierra. Acaray presenta parapetos, bastiones, acceso restringido y piedras para honda en superficie. Reporta además dos fechados radiocarbónicos tomados del material vegetal constructivo del Sector B (muro bajo) y del muro principal del sector C, respectivamente: $790 \pm 70$ BP (ISGS - 5974; 2 sigma: 1159 - 1391 d.C) y $480 \pm 70$ BP (ISGS - 5965; 2 sigma: 1396 - 1628. Ambos fechados calibrados con el programa CALIB 5.0, la curva ShCal04 ), (Brown; 2010: 182, Brown, Craig, Culleton, Kennett, y Asencios; 2013).

Andrzej Krzanowski por su parte menciona la existencia de decenas de sitios de este tipo en los valles de Chancay y Huaura, los cuales son asociados a la cultura Chancay. Para el valle de Huaura registra un total de nueve sitios entre los que figuran: Acaray (Hu-56), Cerro Colorado (Hu-1), Cerro Eriazo A (Hu-80), Cerro Eriazo B (Hu-82), Vista Alegre (Hu-53), Hu-35, Hu-37, Hu-51, y Hu-96; mientras que para el valle de Chancay registra diez sitios, entre los que figuran: Cerro Pasamayo o Castillo de Pasamayo (Ch-3), Cerro San Pedro (CH-7), García Alonso (Ch-14), La Viña (Ch-21), Cerro Las Ondas (Ch-58), Cerro La Calera (CH-60), Cerro Gorgona (CH-54), Cerro San Cristóbal (Ch-43), Ch-17 y Cerro Mascarín (Ch-32). Sobre la funcionalidad de estos sitios, Krzanowski plantea que podría tratarse de sitios ceremoniales o incluso templos, pues no hay rasgos de residencia permanente de personas (con excepción de Acaray), además que los Chancay no se caracterizan por ser belicosos entre ellos, a lo más podría ser para defenderse de sus vecinos (Krzanowski 2008: 75-95).

Krzanowski (2016: 184) analiza la propuesta hecha por varios autores que señalan que estos sitios fortificados pudieron ser erigidos para organizar combates rituales, sirviendo a su vez como templos o sitios para ejercer prácticas rituales y no como defensa de pueblos y territorios; concluyendo que no se puede negar la 
función defensiva de estos sitios, función que podía alternar con la función ritual y ceremonial.

Krzanowski realiza una clasificación de los sitios fortificados, según su complejidad espacial y arquitectónica en los siguientes tipos: ciudadelas, fortalezas, atalayas o puestos de vigilancia o control y murallas extendidas; cada uno con un tipo de construcción diferente. En el caso de las ciudadelas, solo figura el caso de Acaray, se componen de construcciones internas. Las fortalezas o "castillos" se sitúan en colinas rodeadas de murallas concéntricas, pero sin restos de edificaciones internas, o son pocas y distantes entre sí, no hay evidencia de una ocupación permanente, habrían sido edificadas en el Formativo u Horizonte Medio, pero reocupado hasta el Tawantinsuyu, tiene accesos restringidos y sus muros están elaborados en piedra grande en bruto. Los puestos de vigilancia o control son de pequeñas dimensiones, de un solo recinto con doble pared concéntrica (entre 100 y $200 \mathrm{~m}^{2}$ ), ubicados en la cima de los cerros más elevados que circundan el valle desde donde se tiene una vista panorámica del territorio. (Ibid: 82-95).

A partir de las definiciones dadas por los diferentes autores a este tipo de edificaciones es necesario realizar una conceptualización de los mismos: La muralla está definido por el Diccionario de la Real Academia de la Lengua Española como un muro u obra defensiva que rodea una plaza fuerte o protege un territorio. Son todo tipo de fortificaciones edificadas defensivamente para impedir el paso o ataque militar, tratándose de una pared alta, firme y gruesa, de imponente imagen. La función principal era la de proteger y dar seguridad a todas aquellas construcciones ubicadas al interior de su perímetro; aunque había casos en que servían para delimitar un territorio. Pueden ser cerradas (en la mayoría de los casos) o extendidas y abiertas. En algunos casos puede presentar puestos de vigilancia.

El término es un diminutivo de ciudad: ciudad pequeña. Por su parte las fortalezas son aquellas edificaciones fortificadas con fines defensivos militares. Sus orígenes se remontan a la Edad Antigua del Viejo Mundo, como en Roma, siendo luego de uso expandido por toda Europa, como entre los francos y sajones, y ya universalizado en la Europa Feudal. El fenómeno de los sitios fortificados de la alta Edad Media como centros de coerción feudal con una funcionalidad militar, de control del territorio y de las comunidades campesinas, así como los procesos políticos y socioeconómicos que conducen a su nacimiento e implantación, son aspectos ampliamente estudiados en algunas regiones europeas, especialmente en Italia (Gutiérrez y Suárez 2007: 3) y en Polonia (Kajzer 1993).

Como hemos visto en las definiciones, los términos fortalezas y ciudadelas, están referidos a conjuntos arquitectónicos de carácter defensivo, desarrollados principalmente entre finales de la Edad Antigua y la Edad Media, y que simbolizó el sistema feudal imperante en Europa en estos siglos, sistema basado en la relación señor-siervo a través del tributo personal. En este sentido consideramos que estas categorías no pueden ser aplicables para la civilización andina prehispánica, cuyas 
formaciones sociopolíticas tuvieron procesos sociales e instituciones propias. En todo caso el término que más se ajustaría para definir a un sitio o enclave militar, ofensivo o defensivo, sería el pucara. Este tipo de edificación es muy difundido en los periodos Intermedio Tardío y en el Tawantinsuyu, conocido en el Ecuador con el nombre de churu. No presentan un patrón definido, su distribución espacial puede ser variada, pero se denominan así a todos los edificios de carácter militar ofensivo o defensivo, ubicado generalmente en la cima de los cerros (aunque hay algunos en lugares llanos). Las Pukaras fueron ampliamente utilizadas por los cuzqueños en el proceso de conquista de las naciones andinas y su anexión al Tawantinsuyu, así como por estas naciones para defenderse.

El año 2010 Pieter van Dalen (2012b) desarrolló excavaciones en uno de estos sitios con muros concéntricos en el valle Chancay, el Castillo de Pasamayo, sitio ubicado a 3.47 kilómetros de distancia desde la línea de playa. Se trata de un sitio emplazado en un cerro de casi $60 \mathrm{~m}$ de altitud con respecto al fondo del valle, que presenta tres sistemas de muros circundantes concéntricos, que encierran en su interior al llamado conjunto superior, que se encuentra delimitado por el muro perimétrico, de piedras canteadas, con un adosamiento en la parte interna de una banqueta de adobes paralelepípedos e irregulares, de $0.25 \mathrm{~m}$ de ancho y un largo total de $172.78 \mathrm{~m}$ lineales. Ocupa la mitad septentrional de la cima del cerro, de forma irregular, de $50.82 \mathrm{~m}$ de largo (eje norte-sur) por $33.70 \mathrm{~m}$ de ancho (eje este-oeste), con acceso por el lado suroeste mediante un pasadizo en "L" con una rampa. En el lado meridional de la cima hay un espacio a modo de patio, de planta irregular y $36.20 \mathrm{~m}$ de largo (eje este-oeste), por $23.70 \mathrm{~m}$ de ancho (eje norte-sur). Las excavaciones realizadas en la cima de este conjunto superior solo identificaron debajo de la capa superficial de acción eólica, una capa delgada de restos vegetales, no identificando evidencias de alguna función militar.

En base a estas investigaciones en Castillo de Pasamayo y a prospecciones realizadas en el valle de Chancay en sitios similares, van Dalen (2012b) propone que la función de estos sitios no sería militar o defensivo, sino ceremonial; a pesar de que sí existe en los valles de Chancay y Huaura extensas murallas que sí habrían cumplido la función de evitar el avance de huestes enemigas, como las de Mazo en el valle de Huaura, encargado de evitar el avance Chimú (similar a las del valle del Santa (Tello 2004)) y las de Huayán (Villar 1982: 245) y Lumbra en el valle medio del río Chancay (van Dalen 2010). El autor plantea que la función que tuvo el sitio Castillo de Pasamayo fue de carácter religioso. La ubicación de este sitio al igual que muchos otros del valle Chancay denota cierta diferenciación del resto de asentamientos tardíos. Es visible desde todo el sector sur del valle Chancay-Huaral, lo que le da importancia entre los ayllus del sector. Pues los sitios ceremoniales se caracterizan por estar ubicados en puntos estratégicos y que denotan respeto entre los pobladores locales. Mircea Eliade señala que, en los lugares ceremoniales o religiosamente sagrados, se desarrollaron revelaciones primordiales, son lugares 
que destacan en el paisaje o son lugares donde se desarrollaron hechos importantes (Eliade 2000: 522).

Posteriormente, Margaret Brown ha presentado recientes artículos en los cuales plantea el desarrollo de funciones integradas en estos sitios, a partir de las evidencias recuperadas para el valle de Huaura, definiéndolos como sitios multifuncionales: la guerra, las ceremonias de curación y los paisajes sagrados como hilos entrelazados que forman un tejido de cambio cultural (Brown 2015: 103); tratándose de espacios donde se desarrollaban ceremonias de curación de enfermedades, para lo cual se llevaban ofrendas y pagos a las montañas circundantes.

\section{El complejo arqueológico de cerro colorado}

El complejo funerario de Cerro Colorado es el área funeraria más extensa de la Costa Central Peruana, ubicado en el extremo meridional del valle bajo del río Huaura (fig. 1), en el cono de deyección de una quebrada de medianas dimensiones que se une al valle, sobre un terreno arenoso depositado sobre formaciones pétreas de coloración rojiza (Tello 2015). Políticamente se ubica en la localidad de Los

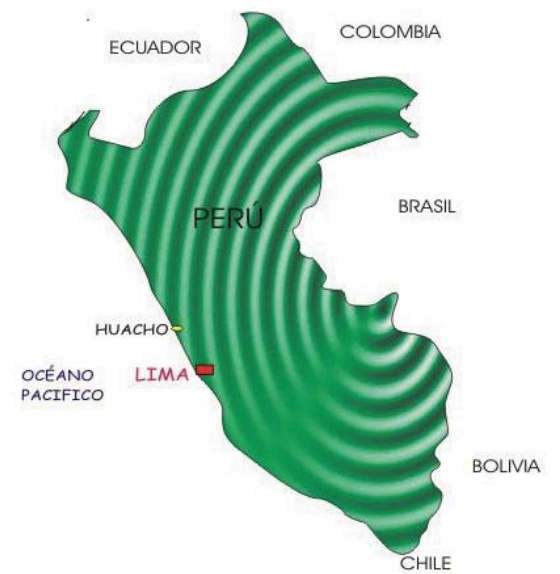

Fig. 1. Mapa de ubicación del complejo arqueológico de Cerro Colorado y la ciudad de Huacho en la Costa Norcentral Peruana. Pinos (ex Asentamiento Humano Alberto Fujimori), distrito de Santa María, provincia de Huaura, región Lima.

La extensión de este cementerio abarcaba entre el Cerro Colorado y gran parte del sector meridional del valle de Huaura, extendiéndose hasta la Playa Colorado, territorio hoy ocupado por numerosos asentamientos humanos y el área de la Ciudad Universitaria de la Universidad Nacional José Faustino Sánchez Carrión (Bueno 2012, Ruiz 1991). Así pues, esta era el área de enterramiento de los antiguos pobladores del valle de Huaura (van Dalen 2015), pues mientras los grandes centros políticos administrativos y residenciales se localizaban en medio del valle, como el complejo arqueológico Walmay (van Dalen 2010, 2012a), su población era enterrada en esta gran área funeraria en medio de grandes rituales.

A pesar que casi no hay arqueólogo que no haya escuchado hablar o haya visitado este complejo de Cerro Colorado, nadie ha realizado investigación arqueológica alguna, pues solo se conocen sus materiales a partir de proyectos de evaluación y rescates arqueológicos (Tosso 2000, Rodríguez 2007, Morales 2009, Vallejo 2010, van Dalen, Grados, Tello, Vivanco, Flores y Marcelo 2014, van Dalen y 
Carbonel 2015, van Dalen, Tello y Grados 2016, van Dalen 2017a, van Dalen y Altamirano 2018) o por la acción del huaqueo.

El área más importante se encuentra ubicado hacia el lado este de la carretera Panamericana, inmediatamente al ingresar a la ciudad de Huacho, terreno que hoy se encuentra ocupado por numerosos asentamientos humanos, los cuales cada año van avanzando y ocupando parte del cementerio huaqueado.

Este complejo arqueológico está dividido en tres grandes sectores:

A. Sector del Cerro con Muros Perimétricos Concéntricos: Se trata de un conjunto de edificaciones ubicadas en la cima del Cerro Colorado que se encuentran circundadas por tres sistemas de muros concéntricos, edificadas a base de piedras canteadas y adobes.

B. Sector del Tambo: Conformado por un conjunto de edificaciones de planta cuadrangular, construidas a base de tapiales, los cuales fueron finalmente pintados de color rojo y crema. Se trata del tambo por donde pasaron los primeros hispanos que se dirigían a Pachacamac a inicios de 1533 (van Dalen 2011).

C. Área Funeraria: Conformado por el extenso cementerio que contiene contextos funerarios con o sin estructuras funerarias (van Dalen 2017a).

\section{El cerro con muros concéntricos de cerro Colorado}

El sector A del complejo arqueológico de Cerro Colorado, conocido como Cerro con Muros Perimétricos Concéntricos (fig. 2), se encuentra ubicado en las coordenadas UTM WGS-84: $217900 \mathrm{E}$ y $8769785 \mathrm{~N}$ (punto tomado en la cima misma del cerro), a una altura de $144 \mathrm{~m}$ sobre el nivel del mar. Desde su base, este promontorio natural tiene una elevación máxima de $26 \mathrm{~m}$, de mediana pendiente, con mayor altitud hacia el lado sur. Está conformado por afloramientos rocosos de

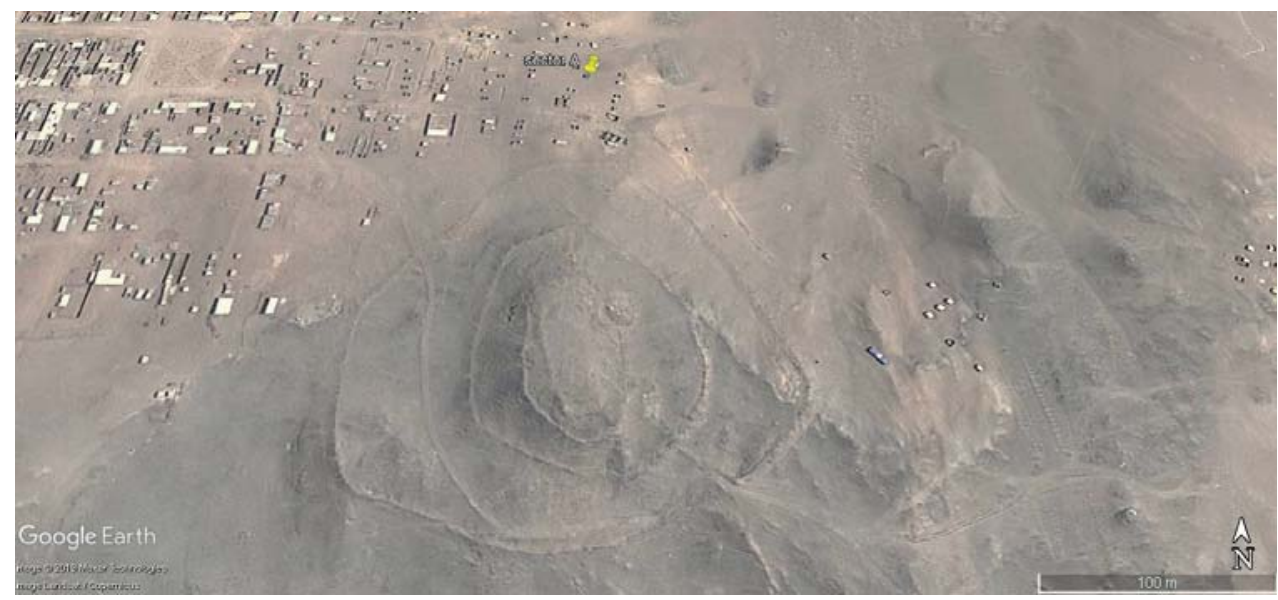

Fig. 2. Cerro Colorado. Vista satelital del sector A del complejo arqueológico. (Google Earth, 2013). 
color rojizo por la composición férrica que presenta y el proceso de oxidación al que ha sido sometido por acción de los agentes naturales (niebla, viento y llovizna). La extensión del cerro es de $352 \mathrm{~m}$ (eje este - oeste) por $521 \mathrm{~m}$ de largo (eje noroeste - sureste), presentando una forma ligeramente triangular, con la punta hacia el lado oeste. Actualmente, toda la base del cerro se encuentra circundada por numerosos asentamientos humanos que desde hace diez años han invadido gran parte de la zona intangible. El área del cerro es de 6.64 Hectáreas, con un perímetro aproximado de $1003 \mathrm{~m}$ lineales.

Andrzej Krzanowski (2016: 194-196) lo identifica dentro de la categoría de fortaleza, a 3.50 kilómetros del litoral Pacífico, compuesta por tres murallas concéntricas, con espacios vacíos entre estas y con falta de huellas de estancia permanente. Ruthenford (2014) y Ruthenford y Ruiz (2011) también lo definen como una fortaleza del Periodo Intermedio Tardío, con tres muros concéntricos en forma de anillos desde la cima, cuya arquitectura presenta basamento típico del Horizonte Temprano (similar a Acaray), con una plataforma superior a base de adobes, sugiriendo el desarrollo de actividades artesanales líticas, cerámica y metálicas en su interior, como actividades cotidianas.

La cima del cerro se encuentra circundada de forma concéntrica por tres muros, cuyas características son:

\section{A.- Muro Perimétrico 1:}

Se encuentra ubicado en la parte superior del cerro, justo debajo del muro de contención de la plataforma que forma la cima misma del cerro. Tiene una longitud de $240.27 \mathrm{~m}$ lineales, con un grosor variable entre 0.20 y $1.80 \mathrm{~m}$ de ancho. Se trata de un muro edificado a base de piedras canteadas y adobes. Sobre este muro y en su interior se excavó tres unidades (fig. 3).

Unidad 9: ubicada junto al Muro Perimétrico 1 (lado norte), en las coordenadas UTM: 217885E, 8769797N. Tiene 6x6 m de dimensiones. La secuencia estratigráfica identificada es la siguiente:

Capa Superficial: Capa de 0.05 a $0.10 \mathrm{~m}$ de grosor, compuesto de material cultural y natural, con una inclinación hacia el oeste. Los materiales culturales son muy escasos (fragmento de cerámica Chancay Llano y material botánico en la parte sureste de la unidad).

Capa A: Capa de arena suelta y gravilla, de color gris amarillento, con inclusiones de rocas angulosas de tamaño pequeño y mediano, textura áspera, con una inclinación hacia el oeste, con un grosor variable entre 0.10 y $0.50 \mathrm{~m}$. Se encuentra fragmentos de cerámica Chancay, material botánico y pocos retazos textiles. Se observa también amontonamiento de rocas y adobitos en el lado sur, junto a la cabecera del muro. En esta capa se encontró el hallazgo 1 (-0.87 m desde la cota), un huso (aguja para hilar) de $15 \mathrm{~cm}$ de largo, que se encontró en el lado oeste de la unidad mezclado con relleno del derrumbe. 


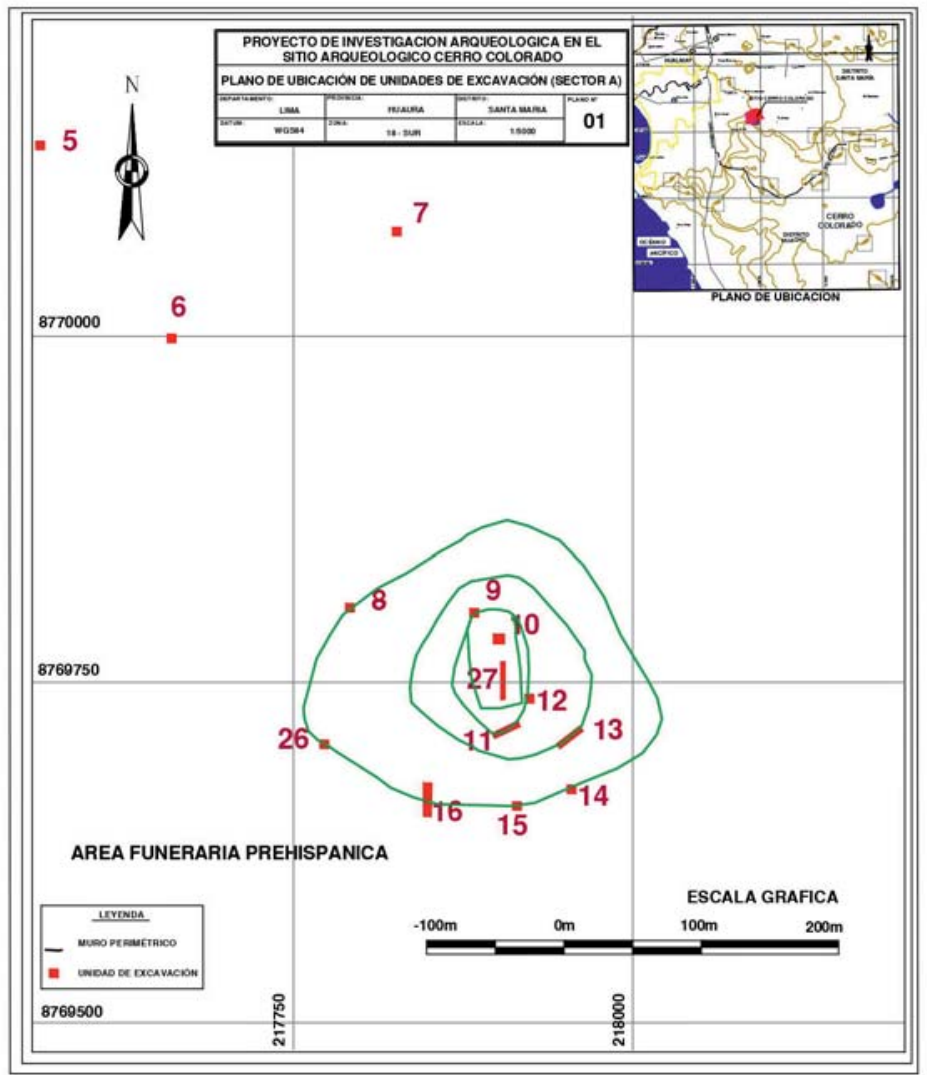

Fig. 3. Cerro Colorado. Plano de ubicación de las unidades de excavación.

Capa B: Capa de origen natural, roca madre de color amarillento con una inclinación hacia el oeste.

En esta unidad, el Muro Perimétrico 1 está edificado mediante mampostería ordinaria con argamasa, de piedras canteadas y adobes, de $0.80 \mathrm{~m}$ de ancho y $0.55 \mathrm{~m}$ de alto conservado.

Unidad 11: Se encuentra ubicada en el lado externo del Muro Perimétrico 1 (en el espacio de ligera pendiente entre este y el Muro Perimétrico 2), en su lado sur. Se trata de una trinchera de $12(\mathrm{E}-\mathrm{W})$ × $2 \mathrm{~m}(\mathrm{~N}-\mathrm{S})$, ubicada en las coordenadas UTM: 217911E, 8769724N. La secuencia estratigráfica identificada es la siguiente:

Capa Superficial: Esta capa es de origen natural, está compuesta por arena eólica, con una coloración beige, de consistencia suelta, textura áspera, mezclado con piedrecillas angulosas. El grosor varía de 0.05 a $0.10 \mathrm{~cm}$.

Capa A: Esta capa es de origen natural, presenta coloración beige, consistencia suelta y textura áspera. Tiene un espesor que varía de $0.05 \mathrm{~m}$ (lado noroeste) 
a $0.10 \mathrm{~m}$ (lado noreste). Presenta inclusiones de materiales culturales: caña brava, panca de maíz, fragmentos de cerámica y material malacológico, distribuidos en casi toda la unidad. En la parte noreste se encuentra piedrecillas angulosas de diferente granulometría, en la parte noroeste se dispone la cabecera del Muro Perimétrico 1.

Capa B: Esta capa está conformada por el Piso 1, asociado al Muro Perimétrico 1 . Se ubica en el lado noroeste de la unidad (cerca al perfil norte), presentándose muy desgastado, de color beige, de textura áspera, y consistencia semi-compacta; con un grosor de $0.03 \mathrm{~m}$, se conserva solo en un pequeño espacio asociado al muro 1.

Capa C: Esta capa está constituida por la roca madre, de tonalidad grisácea.

$\mathrm{Al}$ interior de esta unidad se identificó el muro Muro Perimétrico 1, ubicado en el lado noroeste de la unidad (junto al perfil norte). Tiene una altura de $0.22 \mathrm{~m}$, con un grosor de $0.20 \mathrm{~m}$, muro simple edificado con adobes (de $30 \times 20$ $\mathrm{cm})$. Este muro está emplazado sobre la roca madre. Se encuentra en mal estado de conservación por el colapso de adobes hacia el lado sur del muro. Hacia el lado norte se encuentra asociado al piso 1, donde eventualmente se realizó actividades.

Unidad 12: Se encuentra ubicada en el lado este del Muro Perimétrico 1, emplazado hacia ambos lados del mismo, en la coordenada UTM: 217931E, $8769736 \mathrm{~N}$. Tiene 5 x $5 \mathrm{~m}$ de dimensiones. La secuencia estratigráfica identificada es la siguiente:

Capa Superficial: Esta capa es de origen natural, compuesta por tierra suelta, de color beige, consistencia suelta, textura áspera, mezclado con piedrecillas angulosas. Esta capa tiene un grosor que varía de $0.04 \mathrm{~m}$ a $0.20 \mathrm{~m}$ (lado sureste). No se registró materiales arqueológicos.

Capa A: Esta capa está constituida por arena fina con una coloración beige de consistencia muy suelta y textura áspera, con una coloración grisácea, en la parte media de la unidad se proyecta la cabecera del muro con orientación de sur a norte. El espesor de esta capa varía en el lado oeste de $0.10 \mathrm{~m}$ y en el lado este de $0.03 \mathrm{~m}$. En esta capa se registró material arqueológico junto al muro (material malacológico, material vegetal y fragmentos de cerámica no diagnósticas).

Capa B: Esta capa está conformada por tierra semicompacta, color gris, dispuesta hacia ambos lados del muro perimétrico 1 , de hasta $0.52 \mathrm{~m}$ de grosor. Se encuentra entremezclada con piedras medianas producto del derrumbe del muro.

El Muro Perimétrico 1 en esta unidad se encuentra elaborado con piedras canteadas unidas con argamasa de barro de color gris (fig. 4). Tiene $1.80 \mathrm{~m}$ de ancho, muro doble con relleno interno a base de pequeñas piedrecillas (tipo ripio) y tierra suelta de color beige. Sobre una sección de este muro (lado sur de la unidad) se encuentra tierra muy compactada en áreas con piedras faltantes, conformando un pequeño escalón de tres gradas continuas. Se observa hacia el este de la unidad, 


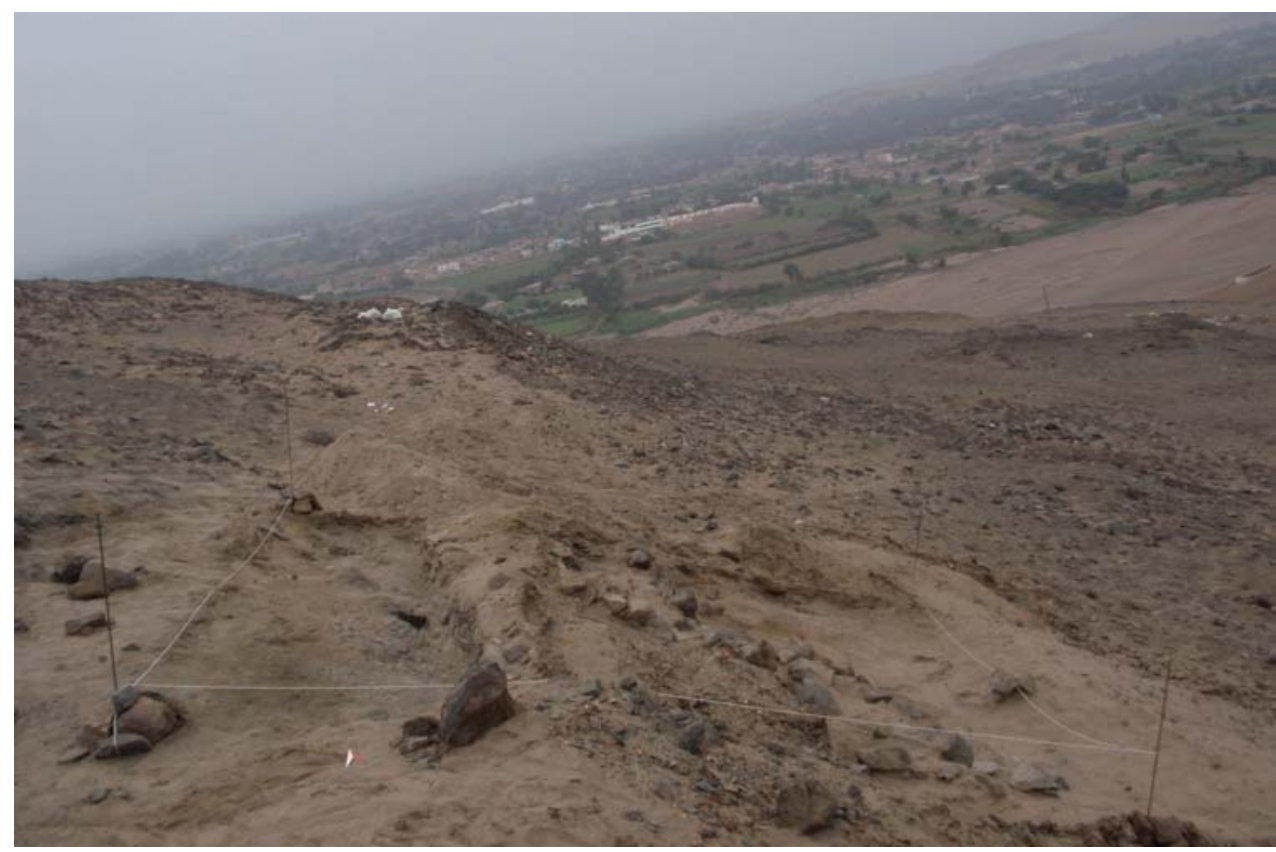

Fig. 4. Cerro Colorado. Vista del Muro Perimétrico 1 con sus tres escalones de acceso, lado sureste (unidad 12).

piedras producto del derrumbe de parte del muro. El muro en esta sección tiene $0.75 \mathrm{~m}$ de alto.

Capa C: Roca madre estéril, de coloración grisácea, de consistencia dura, sobre la cual descansa el basamento del Muro Perimétrico 1.

\section{B.- Muro Perimétrico 2:}

Se encuentra ubicado en la parte media del cerro, a un nivel inferior con respecto al muro 1 (casi a la mitad del cerro). Tiene una longitud de $410.10 \mathrm{~m}$ lineales, con un grosor de $1.80 \mathrm{~m}$ de ancho. Se trata de un muro edificado a base de piedras canteadas unidas con argamasa. En asociación a este muro se excavó la unidad 13, hacia el lado sureste del mismo.

Unidad 13: Se encuentra ubicada en la coordenada UTM: 217961E, 8769732 N. Se trata de una trinchera de $12(\mathrm{~N}-\mathrm{S})$ x $2 \mathrm{~m}(\mathrm{E}-\mathrm{W})$, hacia ambos lados del Muro Perimétrico 2 y con el largo paralelo al muro. La secuencia estratigráfica identificada es la siguiente:

Capa Superficial: Esta capa está compuesta por tierra suelta con una coloración beige, de consistencia suelta, textura suave, mezclado con piedrecillas angulosas, con desnivel hacia el este, con un grosor variable (en el lado oeste es de 0.05 $\mathrm{m}$ y en el lado oeste es de $0.48 \mathrm{~m}$ ). No se registró ningún material arqueológico. 
Capa A: Esta capa es de tierra suelta, de color gris, consistencia suelta y textura áspera, mezclada con piedrecillas. El grosor de esta capa varía de 0.02 $\mathrm{m}$ (lado noroeste) y de $0.20 \mathrm{~m}$ (lado noreste). En la parte noroeste de la unidad se encuentra un delgado apisonado. En el interior de esta capa se halló material cultural compuesto por: caña brava, corontas de maíz, pancas de maíz, fragmentos de cerámica y material malacológico.

Capa B: Está capa está conformada por tierra suelta, posee una coloración beige, consistencia suelta y textura áspera. Esta capa tiene un grosor que varía de 0.10 $\mathrm{m}$ (lado oeste) a $0.17 \mathrm{~m}$ (lado este). En la parte sur de la unidad, junto a la parte externa del muro se halló un apisonado pequeño de consistencia semi-compacta y textura áspera. En esta capa se registra material arqueológico junto al muro, conformado por: material malacológico (choro común, choro azul y almejas), material botánico (caña brava, panca y coronta de maíz) y fragmentos de cerámica no diagnósticos.

El Muro Perimétrico 2 en esta unidad está edificado con piedras canteadas unidas con argamasa de barro, elaborado con hileras irregulares, con orientación de este a oeste, con las caras planas de las piedras dispuestas hacia los paramentos, muro doble con relleno de piedrecillas medianas y tierra suelta de color gris (fig. 5). En la parte media de la unidad (en el lado este) presenta el adosamiento de un pequeño murete de adobes (muro B) intercalado con piedras cerca a la base. Los adobes son paralelepípedos, de $20 \times 35 \mathrm{~cm}$, dispuestos a soga en una sola hilera. Este muro perimétrico se encuentra en regular estado de conservación, se aprecia el derrumbe de piedras y adobes en ambos lados del muro. El ancho del Muro Perimétrico 2 es de $1.80 \mathrm{~m}$ y la altura es de $1.15 \mathrm{~m}$. Entre el paramento este y la parte media del muro, se halló una escalinata interna de tres peldaños (de eje este - oeste), elaborado con adobes paralelepípedos. El muro B está asociado al piso 1, en el cual se realizó una serie de actividades, como la quema posiblemente realizada con motivos rituales (fig. 6).

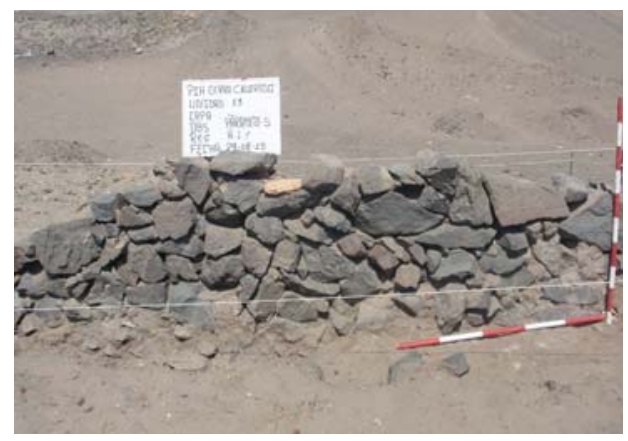

Fig. 5. Cerro Colorado. Vista en detalle del Muro Perimétrico 2 del sector A (unidad 13). Nótese la técnica constructiva.

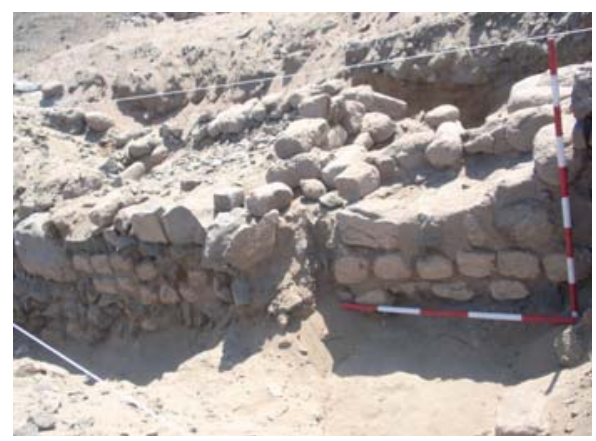

Fig. 6. Cerro Colorado. Vista de detalle del Muro Perimétrico 2 con un piso asociado (unidad 13). Se puede observar los materiales constructivos diversos. 
Capa C: Está capa es la roca madre, de color rojizo, sobre el cual se emplaza el basamento del Muro Perimétrico 2. Se aprecia un piso que se elaboró sobre un delgado lente de ceniza, sobre la roca madre. Este piso está asociado al muro 2, se encuentra en la esquina noroeste de la unidad, muy desgastado, de color beige, textura áspera y consistencia semicompacta.

\section{C.- Muro Perimétrico 3:}

Se encuentra ubicado en la parte baja del cerro, a un nivel inferior con respecto al Muro Perimétrico 2 (casi a la mitad del cerro). Tiene una longitud de $698.15 \mathrm{~m}$ lineales, con un grosor de entre 0.90 y $1.85 \mathrm{~m}$ de ancho. Se trata de un muro edificado a base de piedras canteadas y adobes. Es el muro más externo del sector. En asociación a este Muro Perimétrico 3 se excavaron las siguientes unidades:

Unidad 8: ubicada junto al Muro Perimétrico 3, que en esta área del cerro (lado noroeste), circunda de sur a norte, tratándose de una unidad de 6 × $6 \mathrm{~m}$ de dimensiones, teniendo como centroide la coordenada UTM: 8769894N, 217687E. La secuencia estratigráfica identificada es la siguiente:

La Capa Superficial conformada por arena de color gris, de consistencia semicompacta, acompañada de basura moderna. En esta capa se observa un pequeño tramo de la cabecera del Muro Perimétrico 3, de una sola hilera, edificado a base de piedras canteadas. Esta capa presenta una superficie irregular con una pendiente suave de este hacia el oeste, con inclusiones de fragmentos de cerámica y malacológico, mezclado con gravilla en mínima cantidad.

Capa A: Estrato conformado por derrumbe del muro, con una consistencia compacta, de color gris, acompañado de piedras pequeñas, presenta un pequeño desnivel que va de sur a norte. En este estrato se encuentra material cultural arqueológico como: fragmentos de cerámica, malacológico, fragmentos de adobe, material lítico, óseo animal y material botánico en cantidad mínima. Al interior de esta capa se encontró el hallazgo 1, conformado por un lítico (mano de molienda) de $35 \mathrm{~cm}$ de largo por $23 \mathrm{~cm}$ de ancho, ubicado en la esquina noreste de la unidad (a $0.40 \mathrm{~m}$ ), presentando huellas de uso en la parte inferior, utilizado en actividades domésticas y en buen estado de conservación.

Capa B: Capa semicompacta, presenta una coloración grisácea con intrusión de materiales arqueológicos como: fragmentos de cerámica, malacológicos y material orgánico compuesto. Se observa las características del Muro Perimétrico 3, conformado por un muro de adobes en forma escalonada, orientado de noreste a suroeste, unidos con argamasa de barro. Se aprecia sobre el nivel del muro, un murete de piedras canteadas en una sola hilera, unidas con argamasa. Al interior de esta capa, en la parte interna del Muro Perimétrico (cerca al perfil este y junto al muro), se halló un lente de ceniza, en un área de $0.50 \mathrm{~m}$ por $0.20 \mathrm{~m}$, con un espesor de $0.03 \mathrm{~m}$. Hacia la esquina de los perfiles norte y este hay otro lente de ceniza en 
un área de 0.30 x $0.20 \mathrm{~m}$, de $0.04 \mathrm{~m}$ de espesor, correspondiente a un área de quema, de posibles actividades domésticas.

$\mathrm{Al}$ interior de esta capa se recuperó el hallazgo 4, conformado por un percutor lítico, hallado junto al perfil norte (a $0.60 \mathrm{~m}$ del perfil este y a $0.02 \mathrm{~m}$ del perfil norte). Presenta huellas de uso en uno de los lados, elaborado en roca basáltica, de $15 \mathrm{~cm}$ de largo, $7 \mathrm{~cm}$ de ancho y $5 \mathrm{~cm}$ de grosor. También se recuperó el hallazgo 5 , conformado por un mortero lítico, a $1.45 \mathrm{~m}$ de profundidad desde la cota, ubicado al lado noroeste de la unidad (a $0.80 \mathrm{~m}$ del perfil norte y $2.50 \mathrm{~m}$ del perfil oeste) junto al muro $\mathrm{N}^{\mathrm{o}} 1$. Presenta color beige, elaborado en riolita, con huellas de uso, de $32 \mathrm{~cm}$ de largo, $19 \mathrm{~cm}$ de ancho y $8 \mathrm{~cm}$ de espesor. Por su parte, el hallazgo 6 es otra mano de moler localizada en la esquina noreste (a $0.65 \mathrm{~m}$ de profundidad desde la cota), de $43 \mathrm{~cm}$ de largo, $21 \mathrm{~cm}$ de ancho y $12 \mathrm{~cm}$ de grosor. El hallazgo 7 , consiste en un punzón textil, elaborado en hueso de camélido, hallado en el lado suroeste de la unidad (a $1.10 \mathrm{~m}$ del perfil sur y a $1.20 \mathrm{~m}$ del perfil oeste), a $0.86 \mathrm{~m}$ de profundidad desde la cota, tiene $10 \mathrm{~cm}$ de largo, $2 \mathrm{~cm}$ de grosor, utilizado en la fabricación de textiles, en buen estado de conservación.

El hallazgo 12, está conformado por un saco conteniendo en su interior abundantes hojas de coca, ubicado al interior de la capa $\mathrm{B}$ de relleno, cerca del muro $\mathrm{C}$, a $0.63 \mathrm{~m}$ del perfil sur de la unidad y a $1.83 \mathrm{~m}$ del perfil oeste, a $0.98 \mathrm{~m}$ de profundidad desde la cota (fig. 7). Se trata de un pequeño costalillo de color blanco y llano de algodón, de 1x1 con orillos anillados y unidos en los extremos para formar el costalillo, de $25 \mathrm{~cm}$ de ancho por $19 \mathrm{~cm}$ de ancho. El tejido está deteriorado en algunas partes, pues se encuentra fragmentado. Al interior, las hojas de coca son abundantes y copan la totalidad del interior ajustadamente, con hojas medianas y enteras muy secas por el paso del tiempo (fig. 8). No se halló otro material asociado.

Casi al finalizar este relleno de la capa B, se halló el hallazgo 9, conformado por la ofrenda de un camélido, ubicado a $1.20 \mathrm{~m}$ del perfil este y a $2.80 \mathrm{~m}$.del perfil sur, a una profundidad de $1.04 \mathrm{~m}$ desde la cota (fig. 9). Los restos del camé-

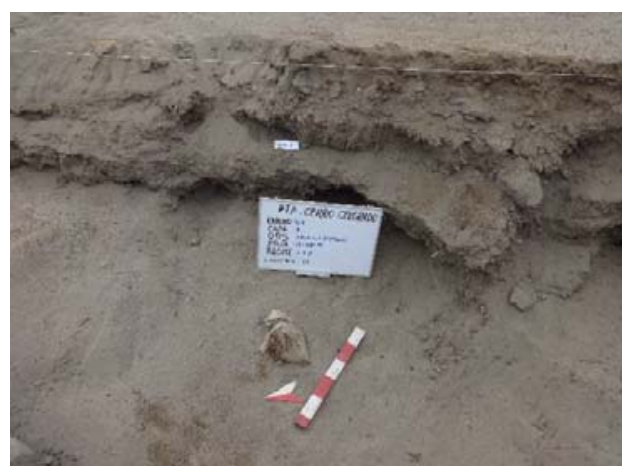

Fig. 7. Cerro Colorado. Hallazgo de un saco con coca junto al Muro Perimétrico 3 del sector A (unidad 8).

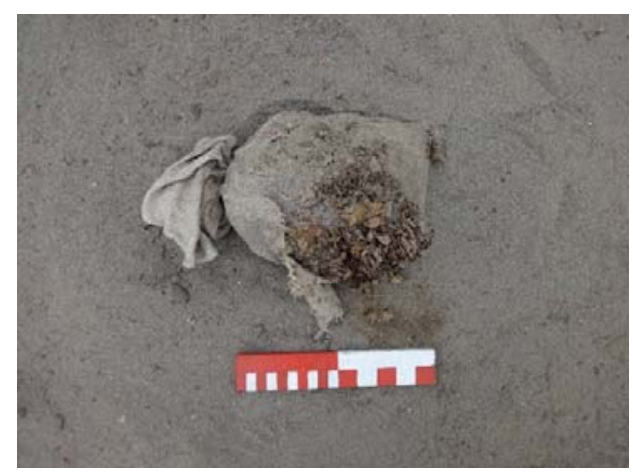

Fig. 8. Cerro Colorado. Detalle del saco con coca (unidad 8). 


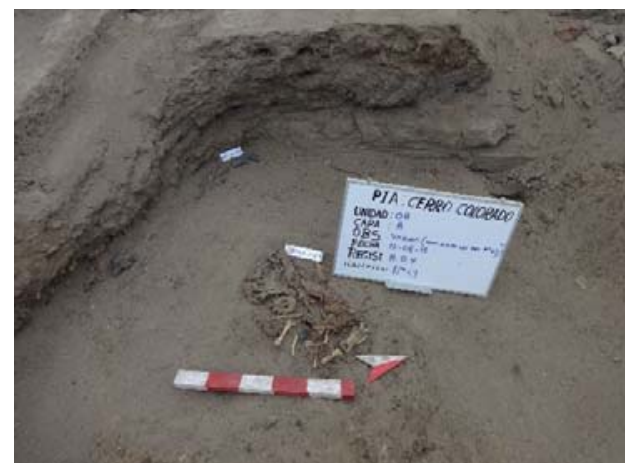

Fig. 9. Cerro Colorado. Vista del hallazgo 9, ofrenda de un camélido (unidad 8).

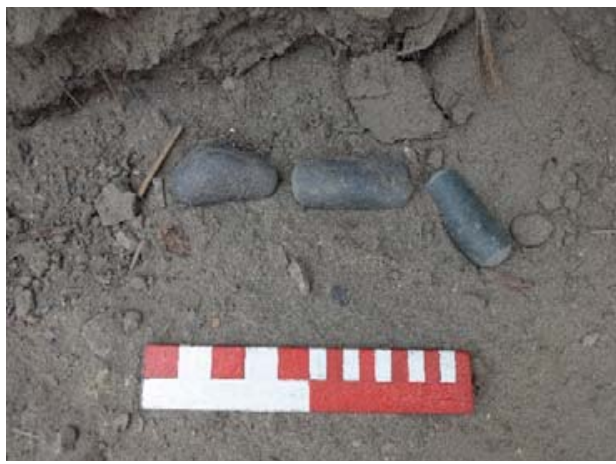

Fig. 10. Cerro Colorado. Vista del hallazgo 10, formado por tres percutores líticos (unidad 8).

lido incompleto, se encuentran envueltos por fardos textiles muy deteriorados, uno de ellos es un tejido llano sin decoración, de fibra de camélido con hilos gruesos retorcidos en $\mathrm{Z}$, de $23 \mathrm{~cm}$ de largo por $10 \mathrm{~cm}$ de ancho; y otro tejido de algodón, con hilos de torsión en $\mathrm{S}$, de $23 \mathrm{~cm}$ de largo por $18 \mathrm{~cm}$ de ancho. En asociación hacia el lado noreste se halló pepas y hojas de lúcuma, pequeñas piedras de basalto color negro y objetos de totora enrollada (una especie de disco de $7 \mathrm{~cm}$ de diámetro).

Casi al mismo nivel de la ofrenda del camélido, pero un poco alejado, se halló el hallazgo 10, percutores líticos, ubicados a $3.20 \mathrm{~m}$ del perfil sur, a unos 2.40 $\mathrm{m}$ del perfil este y a $1.10 \mathrm{~m}$ de profundidad (fig. 10). Se encontró junto al Muro Perimétrico 3. Se trata de tres percutores líticos de forma cilíndrica, con huellas de uso en los extremos, elaborados en piedra basáltica. La primera tiene $7 \mathrm{~cm}$ de largo por $3 \mathrm{~cm}$ de ancho. El segundo también de forma cilíndrica, presenta la superficie pulida, de $4 \mathrm{~cm}$ de largo por $3.5 \mathrm{~cm}$ de ancho, se observan pequeñas fracturas por los golpes y astillamiento. La tercera más pequeña presenta forma irregular, con huellas de uso en uno de los extremos, de $6 \mathrm{~cm}$ de largo por $4 \mathrm{~cm}$ de ancho. Se hallaron al final de la capa B, en la interfacie con la C.

Durante el proceso de excavación de esta capa se hallaron otros eventos de quema, uno de ellos ubicado en el lado sur de la unidad, junto al perfil sur (a $0.20 \mathrm{~m}$ ), en un área de $0.08 \mathrm{~m}$ por $0.05 \mathrm{~m}$, con un espesor de $0.05 \mathrm{~m}$, hallado a $0.70 \mathrm{~m}$ de profundidad de la cota, tratándose de un fogón. De igual manera, a $1.10 \mathrm{~m}$ de profundidad desde la cota, se halló otra área con ceniza, en un área de $0.47 \mathrm{~m}$ de largo por $0.16 \mathrm{~m}$ de ancho y $0.04 \mathrm{~m}$ de grosor; ubicado en el lado sur de la unidad (1.40 m del perfil sur y a $3.40 \mathrm{~m}$ del perfil este), casi debajo de la capa B en la interfacie con la capa C, entre los muros C y D.

Capa C: Estrato natural conformado por la desintegración de la roca madre geológica, de consistencia compacta, coloración beige, se extiende de manera irregular, presenta grietas, con granulometría media fina, conformada por grava y gravilla. 
El Muro Perimétrico 3 al interior de esta unidad se extiende de noroeste a sureste, con un ancho variable ente 0.90 y $1.60 \mathrm{~m}$ (fig. 11). Tiene una altura conservada de $0.64 \mathrm{~m}$ (se observan cuatro hileras). El muro ha sido construido en varios momentos constructivos, de sección escalonada, con adobes paralelepípedos (de entre 0.32 y $0.35 \mathrm{~m}$ de largo, $0.18 \mathrm{~m}$ de ancho y $0.12 \mathrm{~m}$ de alto); los adobes están unidos con argamasa de barro con inclusiones de gravilla y materiales

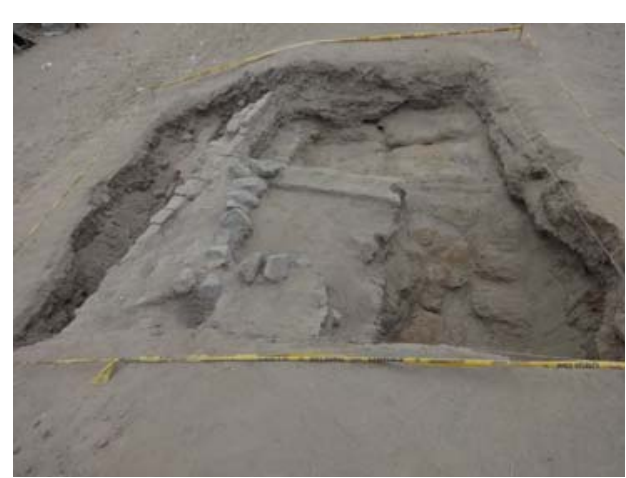

Fig. 11. Cerro Colorado. Vista en detalle de planta del Muro Perimétrico 3 del sector A (unidad 8). arqueológicos (fragmentos cerámicos, moluscos y restos botánicos, incluso la composición de algunos adobes también presenta estos materiales). Los adobes están colocados en el muro en posición de soga y tizón, indistintamente, siendo estos adobes modelados a mano (se observan las huellas de los dedos de los fabricantes). Perpendicular a este muro, casi a la mitad de la unidad, se encuentra el muro D, de adobes, de similares características que el Muro Perimétrico 3 (se adosa a este), de similares dimensiones, de $1.90 \mathrm{~m}$ de largo. Por su parte, el muro $\mathrm{C}$ es un alineamiento de piedras canteadas que se colocaron por encima del nivel del Muro Perimétrico 3.

Unidad 14: ubicada junto al Muro Perimétrico 3 (lado sur), unidad de 8 (N-S) x 7 (E-W) m, con el centroide en la coordenada UTM: 8769662N, 217955E. La secuencia estratigráfica identificada es la siguiente:

Capa Superficial: Capa de arena suelta con inclusión de pequeñas y medianas piedras, ligeramente inclinado hacia el lado sur, de color gris y textura tosca. Se apreció fragmentos de cerámica no diagnóstica, material malacológico y raíces de tillandsias. En esta capa se aprecia la cabecera del Muro Perimétrico 3. Esta capa tiene $0.06 \mathrm{~m}$ de grosor.

Capa A: Capa de arena suelta de color beige, mezclada con piedras angulosas y cascajo, de consistencia suelta. En cuanto a los componentes culturales, presenta en mínima densidad: fragmentos de cerámica, material textil, malacológico (en mínima cantidad), soguillas de fibra vegetal y material botánico (chala de maíz, caña y corontas de maíz, fragmento de mate, cabello humano y algodón de color marrón). Esta capa tiene entre 0.03 y $0.15 \mathrm{~m}$ de grosor. Al interior de esta capa se identificó el hallazgo 1, conformado por un adorno elaborado de mate, ubicado a $0.50 \mathrm{~m}$ al sur del perfil norte y a $2 \mathrm{~m}$ al este del perfil oeste. De igual manera, el hallazgo 2, conformado por un artefacto de madera chonta (callhua o espada para tejer en telar, muy común al interior de los contextos funerarios de individuos femeninos del sector $\mathrm{C}$ de Cerro Colorado), recuperado a $0.40 \mathrm{~m}$ al sur del perfil norte y a $1.50 \mathrm{~m}$ al este del perfil oeste. 
Capa B: Capa de tierra mezclada con abundante material botánico, dispuesto solo en la parte norte de la unidad (cara interna del Muro Perimétrico 3); mientras que hacia el lado sur hay más presencia de arena fina mezclada con piedras pequeñas (del colapso del muro). Capa de consistencia semicompacta, con un espesor de entre 0.04 y $0.20 \mathrm{~m}$. Los componentes culturales ubicados en esta capa son material orgánico descompuesto. En esta capa se expone los paramentos completos del muro.

Capa C: Capa de arena suelta con inclusión de pequeñas piedras, con un espesor de entre 0.02 y $0.05 \mathrm{~m}$, color beige, cuya homogeneidad es ligeramente uniforme. Se registró inclusión de fragmentos de cerámica, vegetal, malacológico y carbón.

Capa D: Se trata de la roca geológica, de color gris.

El Muro Perimétrico 3 identificado en esta unidad tiene dirección esteoeste. Este muro tiene $1.85 \mathrm{~m}$ de grosor y una altura de $1.30 \mathrm{~m}$, de regular estado de conservación, edificado a base de piedras canteadas unidas con argamasa, con inclusiones de pequeñas pachillas (fig. 12). En el paramento este se aprecia que, entre las hileras horizontales de piedras, presenta en vez de argamasa, una capa de $0.10 \mathrm{~m}$ de grosor de restos vegetales (tillandsia y junco). El muro es doble con relleno interno de piedras medianas y tierra.

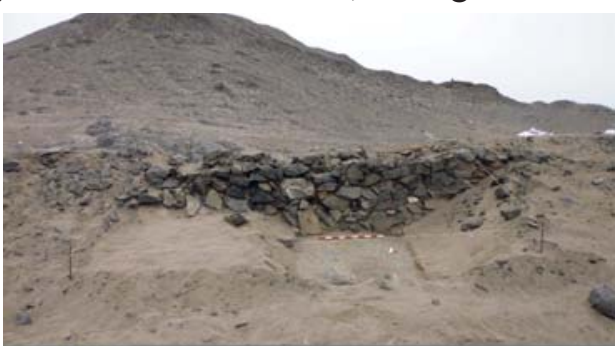

Fig. 12. Cerro Colorado. Vista del Muro Perimétrico 3, lado sur (unidad 14)..

Unidad 15: se encuentra ubicado en el lado sur del muro perimétrico 3, en las coordenadas UTM: $217916 \mathrm{E}$ y $8769676 \mathrm{~N}$, con dimensiones de 5 x $5 \mathrm{~m}$. La secuencia estratigráfica identificada es la siguiente:

Capa superficial: Capa de arena suelta con inclusión de pequeñas y medianas piedras y gravilla, de relieve ligeramente inclinado hacia el sur. Se recuperó algunos fragmentos de cerámica y materiales orgánicos. Al retirar esta capa se aprecia la cabecera del muro perimétrico. Esta capa tiene un grosor de $0.06 \mathrm{~m}$.

Capa A: Está conformado por arena suelta mezclada con pequeñas piedras, de color beige y textura áspera. En cuanto a los componentes culturales hay poca densidad de fragmentos de cerámica diagnóstica (Chancay Base Crema) y no diagnostica, material malacológico, líticos (núcleos de basalto, cuarzo lechoso y transparente) y fragmentos o terrones de adobe. También se aprecia raíces de tillandsia sp., cabello humano y pequeños grumos de algodón. El grosor de la capa es entre 0.05 y $0.20 \mathrm{~m}$.

Capa B: Se ubica a $0.04 \mathrm{~m}$ al interior de esta capa, presenta arena suelta fina de color beige y pequeñas piedras angulosas (principalmente en el lado norte) producto del colapso de parte del Muro Perimétrico. Capa de consistencia suelta, de granulometría variada y textura áspera. El material cultural mueble tiene mayor 
densidad en el lado norte, contiguo al Muro Perimétrico 3, conformado en su mayoría por fragmentos de cerámica de estilo Chancay y fragmentos de adobe quemado. El grosor de la capa varía entre 0.08 y $0.20 \mathrm{~m}$. Debajo de la capa B se encuentra la roca madre (capa C), de color gris.

Lente de ceniza 1. Está ubicado junto al perfil oeste, junto a la cara interna del muro perimétrico (que presenta huellas de quema a esta altura), evidenciándose en su interior fragmentos de cerámica de estilo Chancay, material botánico (corontas de maíz y paja) y un terrón de adobe. Se ubica junto al vano de acceso.

Lente de ceniza 2. Se sitúa junto al perfil este, junto a la cara interna del muro 2 (evidencia huellas de quema), casi al mismo nivel que el primero. Se halló al interior fragmentos de cerámica de estilo Chancay y material botánico.

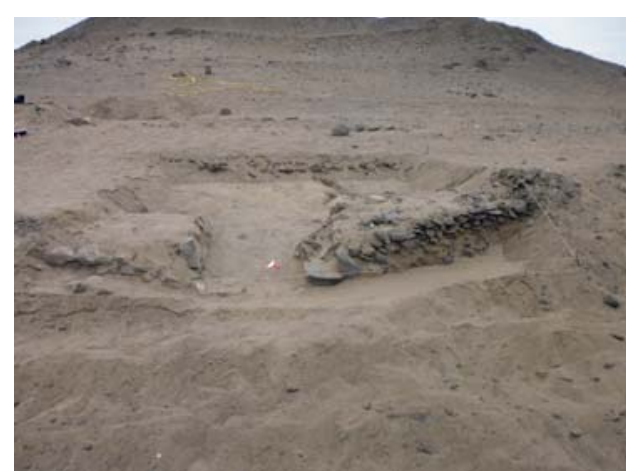

Fig. 13. Cerro Colorado. Vista del vano de acceso al Muro Perimétrico 3, lado sureste (unidad 15).

En esta unidad el Muro Perimétrico 3 presenta un acceso de $1.90 \mathrm{~m}$ de ancho (fig. 13). Este muro tiene dirección este-oeste, discurre en el lado este de la unidad, en regular estado de conservación. Está conformado por piedras y adobes, mezclados en el mismo muro, mampuestos con argamasa. Los adobes son los típicos Chancay. El basamento se emplaza sobre la roca. Tiene un ancho de $1.68 \mathrm{~m}$, con una altura conservada de entre 0.45 y $0.50 \mathrm{~m}$. Se trata de un muro doble con relleno intermedio. En el caso de la sección ubicada hacia el este del vano, el paramento externo no recibió ningún tratamiento y muestra aparejo regular a base de piedras pequeñas; mientras que el paramento interno presenta las dos primeras hiladas a base de adobes rectangulares unidos con argamasa, mientras que a partir de la tercera hilada presenta pequeñas piedras unidas con argamasa.

La sección ubicada al oeste del vano se encuentra en regular estado de conservación. Está edificado, al igual que la otra sección del Muro Perimétrico 3 , a base de piedras canteadas y adobes, unidos con argamasa. También presenta en el paramento externo solo piedras, con pachillas intermedias unidas con argamasa, mientras en el paramento interno se aprecia adobes con huellas de quema (primera hilada) y piedras (desde la segunda hilada). Este muro es doble, tiene $1.50 \mathrm{~m}$ de ancho, con una altura entre 0.20 y $0.50 \mathrm{~m}$.

Unidad 16: Se encuentra ubicado en el lado sur del cerro, con centroide en las coordenadas UTM: 8769694N, 217852E. Se trata de una trinchera de $12(\mathrm{~N}-\mathrm{S})$ por $2 \mathrm{~m}$ (E-O).

Capa superficial: Capa eólica de arena suelta de un grosor entre 0.05 y $0.44 \mathrm{~m}$. 
Capa A: Capa de arena mezclada con tierra, de consistencia semicompacta, textura áspera y de color beige. La distribución de la capa se presenta irregular y discontinua, con un ligero desnivel en orientación noreste a suroeste. Esta capa tiene un grosor de entre 0.02 y $0.26 \mathrm{~m}$. En su interior se recuperó restos botánicos con indicios de quema, fragmentos de cerámica y trozos de adobes.

Capa B: Capa de relleno, compuesta de arena mezclada con tierra con indicios de quema, se extiende irregularmente, de consistencia semicompacta y de color beige. El espesor es de $0.03 \mathrm{~m}$. Se trata de un apisonado que se convierte en revoque adosado al muro, elaborado con mortero color beige de textura suave. Se halló al interior de esta capa restos botánicos (cañas, fragmentos de mate, frijol, panca y tuzas de maíz); restos malacológico, óseo animal, textil, soguillas, parte de una honda y boleadoras asociadas a áreas de quema. Después de esta capa se aprecia la capa de origen geológico, compuesto por roca de color gris claro.

Al interior de esta unidad se observó las características del Muro Perimétrico 3 , se trata de un muro doble con relleno de piedrecillas intermedio (fig. 14). Está edificado a base de adobes paralelepípedos e irregulares asentados a soga en la parte inferior del muro (en ambas caras) y a tizón en la parte superior. Este muro discurre en dirección noroeste a sureste, con una altura máxima de $0.46 \mathrm{~m}$, con un ancho de $1.40 \mathrm{~m}$. El estado de conservación es muy malo, producto de alteraciones antrópicas $\mathrm{y}$ climáticas.

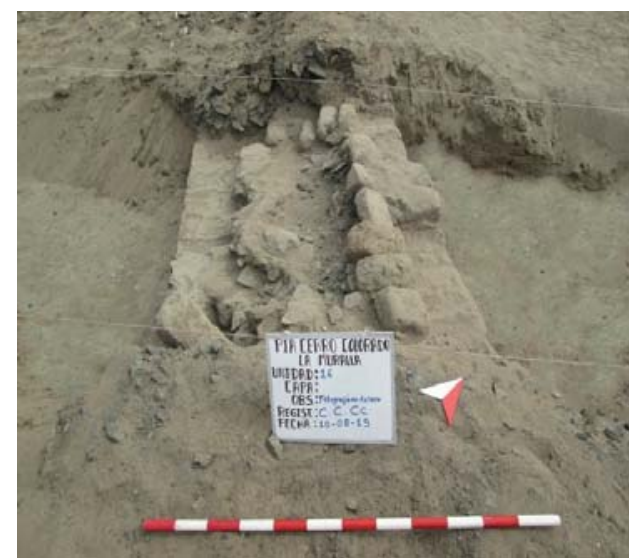

Fig. 14. Cerro Colorado. Vista del Muro Perimétrico 3 (unidad 16).

Unidad 26: se encuentra ubicado en el lado suroeste del cerro, sobre una pequeña lomada intermedia del cerro, con centroide en las coordenadas UTM: $8769722 \mathrm{~N}, 217804 \mathrm{E}$. Se trata de una unidad de 7 x $7 \mathrm{~m}$, ampliada 1 metro hacia su lado sur. Se halló un recinto que abarca casi toda la unidad, el cual está adosado al muro perimétrico y aprovechándolo. La secuencia estratigráfica del interior del recinto es:

Capa superficial: Capa eólica de arena suelta mezclada con basura moderna, con inclusión de piedras angulosas pequeñas. Tiene consistencia suelta, con presencia de fragmentos de cerámica de estilo Chancay, material malacológico (almeja, choritos, choro azul, fisurela, chanque y otros) y raíces de tillandsia sp. Tiene un grosor de $0.10 \mathrm{~m}$.

Capa A: Relleno de arena de consistencia semisuelta, granulometría fina, color beige y textura áspera. En cuanto a componentes culturales presenta mínima densidad de fragmentos de cerámica, material textil, malacológico, lítico, soguilla 


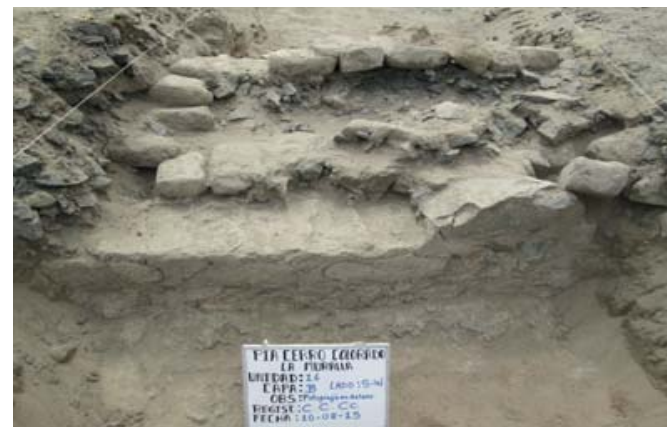

Fig. 15. Cerro Colorado. Vista de otro sector del Muro Perimétrico 3, lado oeste (unidad 26).

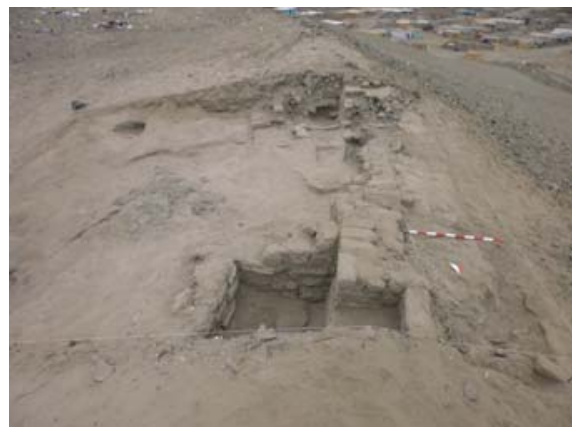

Fig. 16. Cerro Colorado. Vista panorámica del Muro Perimétrico 3 con el recinto adosado (unidad 26).

de fibra vegetal, terrones de adobe, un fragmento de mate, cabello humano y algodón de color marrón. Tiene un espesor de $0.16 \mathrm{~m}$.

Capa B: piso compacto, elaborado de arcilla con inclusión de pequeñas piedras, de entre 0.02 y $0.04 \mathrm{~m}$. Es de color beige, textura ligeramente lisa, homogeneidad variada. Está asociado con todo el recinto y sus muros (interior del recinto), ubicados al lado noroeste de la unidad. Debajo de la capa B (piso) se encuentra la roca madre de color gris.

El Muro Perimétrico 3 en esta unidad se comienza a apreciar bien desde la capa $A$ hasta la capa $B$, teniendo su basamento sobre la roca madre (fig. 15). Adosado en la parte interna del muro se encontró un habitáculo de planta rectangular, de $1.30 \mathrm{~m}$ de largo por $1.10 \mathrm{~m}$ de ancho (fig. 16). Los tres muros al igual que el Muro Perimétrico 3 están edificados a base de adobes paralelepípedos, tratándose de muros dobles, de entre 0.52 y $0.58 \mathrm{~m}$ de ancho, presentando una altura conservada de hasta $0.58 \mathrm{~m}$ de alto, todos en mal estado de conservación. Algunos sectores de los paramentos internos presentan enlucido de color crema. El acceso se da por la esquina sureste del recinto, mediante un vano al que se accede mediante una grada.

\section{D.- La cima del cerro}

Es un espacio que se encuentra circundado por un muro de contención de plataforma, ubicado por encima del nivel del Muro Perimétrico 1, edificado con el objetivo de nivelar horizontalmente el terreno. Este muro al elevarse hasta el nivel de la plataforma, continúa elevándose, convirtiéndose en un muro doble, destinado a delimitar el espacio interno de la cima. En el lado suroeste presenta un muro que se desprende del Muro Perimétrico y se eleva por sobre el nivel de este, dando horizontalidad al espacio interno. El espacio interno tiene $82.48 \mathrm{~m}$ (norte - sur) por $34.45 \mathrm{~m}$ (este - oeste), con un perímetro de $217 \mathrm{~m}$ y un área de $2804 \mathrm{~m}^{2}$. Este muro estaba edificado a base de adobes paralelepípedos, conformado por un muro simple, con una altura conservada de $0.20 \mathrm{~m}$. Desde esta cima se tiene una vista privilegiada de todo el valle bajo del río Huaura y del litoral huachano. 
Unidad 10: ubicada al interior de la cima del cerro (lado noreste), en las coordenadas UTM: 217901E, 8769780N. Tiene 7x7 m de dimensiones. La secuencia estratigráfica identificada es la siguiente:

Capa superficial: Estrato de consistencia suelta, con coloración beige, conformado por arena de origen eólico y gravilla fina. Presenta inclusiones de material malacológico. Tiene un grosor de 0.02 a $0.04 \mathrm{~m}$.

Capa A: Capa suelta de arena y tierra de color beige, entremezclado con gravilla fina, con inclusiones de material cultural (tusas de maíz, caña, malacológicos, fragmentos de tejidos y cerámica de estilos Chancay), homogénea en la toda la superficie. Tiene $0.04 \mathrm{~m}$ de grosor.

Capa B: Capa compacta conformado por un piso elaborado sobre la capa estéril, a base de tierra arcillosa, abarcando desde la parte media de la unidad hasta el sureste, de granulometría muy fina, con inclusiones de gravilla. El piso se halló disturbado, quedando una pequeña franja, al parecer se entendía por toda la unidad. En actividad con el piso se halló material botánico en descomposición y pequeños fragmentos de cerámica. Tiene un grosor de $0.05 \mathrm{~m}$. Debajo de la capa B (piso) se encuentra la roca madre de color gris.

Unidad 27: Trinchera ubicada al interior de la cima del cerro (parte media), distribuyéndose con su mayor longitud en el eje norte - sur, en las coordenadas UTM: 217904E, $8769750 \mathrm{~N}$. Tiene 12x2 m de dimensiones. Esta trinchera se elaboró para conocer, al igual que la unidad 10, que tipo de contextos y materiales había al interior del espacio cercado, en la misma cima del cerro. La secuencia estratigráfica identificada es la siguiente:

Capa superficial: Capa eólica de arena fina con inclusión de pocas pequeñas piedras y material arqueológico como: malacológico, piedras regulares con impregnaciones de sal, fragmentos de adobes paralelepípedos, fragmentos de cerámica (pasta color rojo oscuro y naranja, del estilo Chancay y Lauri Impreso), material botánico (troncos de caña, vainas de fréjol, achira, tusas de maíz, fragmentos de mate), trozos de algodón (de coloración azul y marrón). El grosor de esta capa es entre 0.02 y $0.09 \mathrm{~m}$, presentando una superficie irregular ondulante.

Capa A: Conformado por un piso elaborado de tierra semicompacta color beige, elaborado sobre la roca madre y de entre 0.04 y $0.07 \mathrm{~m}$ de grosor, muy deteriorado en varias secciones y desplazado por acción del intemperismo y el huaqueo (fig. 17). Presenta en varias áreas restos de adobes paralelepípedos fragmentados, observándose inclusión de materiales arqueológicos (botánico,

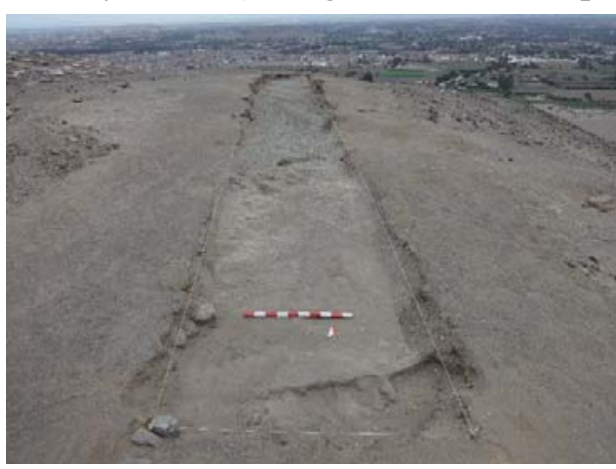

Fig. 17. Cerro Colorado. Vista del final de excavación de la unidad 27 , trinchera en la cima del sitio. Nótese el piso sobre la roca madre. 
fragmentos cerámicos, malacológico y óseo animal). Sobre esta capa se recuperó tres hallazgos: El hallazgo 1 correspondiente a un fragmento de quena (elaborado en caña, de $22 \mathrm{~cm}$ de largo y con seis agujeros), ubicado a $4 \mathrm{~m}$ del perfil norte y a $0.90 \mathrm{~m}$ del este, entremezclado con los fragmentos de adobe, botánico y fragmentos cerámicos. El hallazgo 2 es un pequeño piruro, hallado a $0.45 \mathrm{~m}$ al suroeste del primero. El hallazgo 3 es un pequeño lente de ceniza con trozos de carbón quemados sobre el piso, a 1.00 metro del perfil oeste y $0.80 \mathrm{~m}$ del norte, de $0.02 \mathrm{~m}$ de grosor y en un área de $0.06 \times 0.08 \mathrm{~m}$. Debajo del piso se halla la capa B, conformada por la roca madre gris, con ligero desnivel de sur a norte, con grietas rellenas de arena blanquecina gravilla o ripio.

\section{Los materiales culturales recuperados de las excavaciones}

Las excavaciones realizadas permitieron recuperar abundante material cultural arqueológico. Entre el material botánico se recuperó: Ipomoea batatas (camote), Arachis hypogaea (maní), Zea mays (maíz), Vicia faba (habas), Phaseolus vulgaris (frijol), Phaseolus lunatus (pallar), Manihot esculenta (yuca), Canna edulis (achira), Capsicum sp (ají), Cucurbita máxima (zapallo) y Pachirrhyzus tuberosus (jiquima). Entre los frutales identificados figuran: Bunchosia armeniaca (ciruela del fraile), Pouteria lúcuma (lúcuma), Erythrina edulis (poroto), Inga feuillei (pacay), Psidium guajava (guayaba), Persea americana (palta), Annona cherimola (chirimoya) y Eriobrotria sp. (níspero). Entre las plantas industriales se ha identificado: Gossypium barbadense (algodón), Fuchsiamegallanica (chilca), Lagenaria siceraria (mate), Typha domincensis (totora), Phragmites australis (carrizo), Scirpus lacustris (junco), Gynerium sagittatum (caña brava), Prosopis palida (huarango), Sapindus saponaria (choloque), Prosopis juliflora (algarrobo) y Tillandsia sp (achupalla), (fig. 20).

Entre las especies malacológicas identificadas figuran: Aulacomya ater, Choromytilus chorus, Mesodesma donacium, Crepidula dilatata, Bostryx sp.,

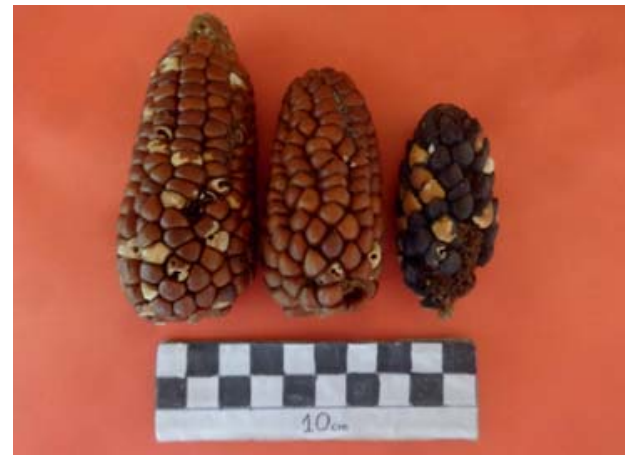

Fig. 18. Cerro Colorado. Vista de varios tipos de maíz recuperado de las excavaciones.

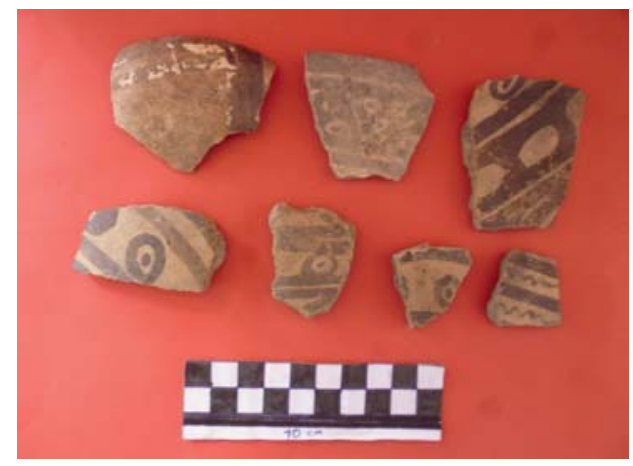

Fig. 19. Cerro Colorado. Fragmentería cerámica de estilo Chancay del tipo Negro sobre Blanco. 
Perumytilus purpuratus, Thais chocolate, Polinecis uber, Aeneator sp., Semimytilus algosus, Prisogaster niger, Chitón sp., Concholepas concholepas, Semele solida, Fissurella limbata, Argopecten purpuratus, Turritela sp., Tegula atra, Placa de Chitón sp., Mulinia edulis, Oliva sp., Eurhomalea rufa, Venus antiqua, Prisogaster niger, Sinum cymba, entre otras.

Entre los restos faunísticos hallados en las excavaciones figuran restos

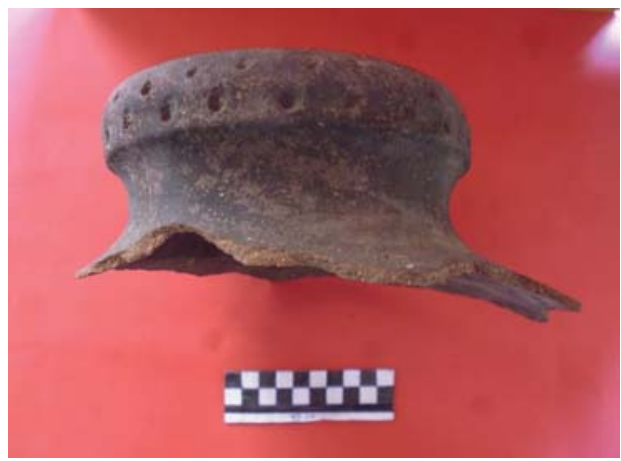

Fig. 20. Cerro Colorado. Fragmento cerámico de estilo Lauri Impreso. de: venado de cola blanca (Odocoileus virginianus), llamas, alpacas, perro (Canis familiaris), peces (jurel, ballena, bonito, atún grande, pez espada, anchoveta, suco), cuy (Cavia porcellus), aves de litoral (gaviota, piquero, pelícano), nutria o "chungungo" (Lutra felina), gallinazo (Coragyps atratus), roedor costeño o ukush (Phyllotis pictus), entre otros.

Sobre el material cerámico, predominan los fragmentos de estilo Chancay, principalmente de los tipos Negro sobre Blanco y Base Crema. Se recuperó también fragmentería cerámica de los estilos Lauri Impreso y Huacho, Pativilca, Chancay Tricolor y Huaura. En la cima se recuperó fragmentos de estilos Chancay Negro Sobre Blanco, Inca Local y Lauri Impreso (fig. 18, 19).

\section{Interpretaciones de las actividades y funcionalidad del sitio}

Las investigaciones con excavaciones desarrolladas en el sector A de Cerro Colorado, conformado por un cerro con muros concéntricos han dado resultados importantes, para la comprensión del significado e importancia de este tipo de asentamientos de la cultura Chancay. Pues, como hemos visto líneas arriba, este tipo de asentamientos han sido caracterizados por investigadores como Andrzej Krzanowski y Margaret Brown como fortificaciones defensivas, relacionadas con la protección en tiempos de guerra; pudiéndose desarrollar algunas actividades ceremoniales en tiempos de paz. Sin embargo, los datos recuperados de nuestras excavaciones en este sitio del valle de Huaura revelan que habrían cumplido otra función. No se ha encontrado armas de guerra ni proyectiles en el interior de este sector y áreas contiguas a los muros perimétricos; como si se han encontrado, por ejemplo, porras y proyectiles en el sector B de Cerro Colorado de filiación Tawantinsuyu (Tambo).

Así mismo, las características y dimensiones de los muros perimétricos concéntricos que circundan la cima del Cerro Colorado (sector A), no son sólidos e infranqueables; al contrario, no presentan homogeneidad en cuanto a sus materiales 
y técnicas constructivas; pues en algunos segmentos un mismo muro presenta adobes y en otras piedras canteadas, en un sector presenta un muro simple de $0.25 \mathrm{~m}$ de grosor y en otros se trata de un muro doble de hasta $0.80 \mathrm{~m}$ de ancho; aprovechando en algunos casos los afloramientos rocosos (sobre todo en los muros perimétricos 1 y 2), produciéndose interrupciones murarias. La altura original de estos muros se ha perdido, pero es posible que haya tenido hasta $1.80 \mathrm{o} 2.00 \mathrm{~m}$ de altitud. No tuvieron mayor altitud, debido a que por sus características constructivas no hubiera tenido soporte y fácilmente hubiera colapsado. En cuanto a los vanos de acceso, los principales se hallaban orientados hacia el lado oeste: el del Muro Perimétrico 3 se hallaba en el lado noroeste, identificado en la unidad 8, aunque hay otro vano en el mismo muro ubicado en el lado sureste de $1.90 \mathrm{~m}$ de ancho (unidad 15); el del Muro Perimétrico 2 se hallaría también por este lado, al igual que el primero (aunque en el Muro Perimétrico 1 se identificó un acceso simple formado por tres escalones continuos de piedra que ascienden por el muro de piedras, en la unidad 12). En caso de una invasión, estos muros hubieran sido fácilmente superados, para acceder a la cima, cuyo espacio interno (con un área de casi $2000 \mathrm{~m}^{2}$ y muchos desniveles) no podría albergar a una fuerza mayor a 500 personas a duras penas.

Las investigaciones realizadas en las últimas décadas en los Andes vienen fortaleciendo el planteamiento que el Periodo Intermedio Tardío fue un periodo de constantes conflictos; por ello, la mayoría de culturas altoandinas emplazaron sus pueblos en la cima de los cerros más elevados, de difícil acceso y circundado por inaccesibles sistemas de murallas (van Dalen 2016). Los análisis forenses a los cuerpos humanos evidencian alto índice de traumatismos y muerte por golpes. Sin embargo, para el caso de la Costa Central, la excavación de áreas funerarias no evidencia a individuos con altos índices de violencia, tampoco las fuentes etnohistóricas revelan información sobre conflictos internos y externos. Del análisis de más de 1700 individuos del cementerio de Cerro Colorado (sector C), solo se identificó que menos del $2 \%$ de individuos presentaban trauma por violencia; siendo un porcentaje igual de la población analizada en el sitio de Macaton (valle de Chancay). En Macatón igualmente. La dominación incaica se habría dado de manera pacífica en esta región, aduciendo a la estrategia pacífica mediante una dominación indirecta; motivo por el cual el estado Tawantinsuyu no edificó asentamientos de control en esta región (Krzanowski 1990, van Dalen 2016).

Debemos considerar la ubicación estratégica de este sitio, ubicado por encima de un terreno plano arenoso de color rojizo, en el cual se habilitó desde el Horizonte Medio, el área funeraria más grande de la Costa Central Peruana, donde se hallan depositados decenas (talvez centenares) de miles de individuos de la cultura Chancay que vivieron en este valle de Huaura; además, por su altitud, se constituye en una de las últimas estribaciones andinas del extremo meridional del valle de Huaura, fácilmente visible desde cualquier sector del valle bajo y desde la línea de playa. Desde la cima de este cerro se tiene a su vez, una vista panorámica de la línea 
de playa, del litoral de Huacho y de todos los asentamientos Chancay del valle bajo, teniendo una vista privilegiada.

Las características que presenta este sitio no son particulares, existen muchos otros asentamientos de la cultura Chancay de similares características, ubicados entre los valles medio y bajo de Chancay y Huaura, siendo la gran mayoría visibles hasta el litoral o hasta el río. Por ello, planteamos que estos asentamientos habrían cumplido una función ceremonial, relacionados con el culto al mar. El culto al mar o Mamacocha y a Urpiwachak fue muy importante para las sociedades prehispánicas tardías de la Costa Central Peruana (Rostworowski 1973), siendo divinidades que proveía a los pobladores de cuantiosos recursos, en especial los peces. Valdemar Espinoza (1997: 458) señala que Mamacocha velaba por el sostenimiento humano y estaba relacionado no solo con la pesca, sino también con la agricultura (al igual que el dios Auca Atama). El culto a Urpiwachak se relacionaba con el de Mamacocha, tan es así que muchas veces se tornaba en el mismo culto. Rostworowski (2005: 160) señala que uno de los templos donde se desarrollaba el culto a Urpihuachak se situaba en el cerro Punchao Cayán (se desconoce si se trata del valle de Lurín o Chancay), en el lugar denominado Camahirca, donde ascendían los pobladores locales a pedir el incremento de lluvias y que abastezca de suficientes peces a la población local.

La religión era la base de la vida diaria de la población andina, en todos sus sistemas de organización, en especial con las actividades económicas de subsistencia (Espinoza; 1997). Las divinidades familiares, locales, nacionales y regionales eran invocadas en el desarrollo de toda actividad: antes de salir a la pesca, antes de sembrar o cosechar, antes de iniciar una jornada comercial, antes de elaborar implementos artesanales, antes de una ceremonia social o deportiva; en todos los casos se invocaba a las divinidades tutelares y protectoras de cada ayllu, esperando que con esto se tenga el beneficio protector de estos dioses y todas las actividades planificadas sean realizadas con éxito. Por ello, por todo el territorio de un ayllu había numerosos sitios ceremoniales, como: huacas, apachetas, apus o wamanis, jirkas, etc; que se complementaban con las áreas productivas y las áreas de residencia.

Ahora, volviendo al caso del sector A del complejo arqueológico de Cerro Colorado y otros sitios que presentan el mismo patrón, su caracterización encaja perfectamente a otros sitios que han sido definidos como sitios de función ceremonial. En los Andes los cerros fueron objeto de culto, estos apus o wamanis fueron considerados entes protectores de todas las poblaciones circundantes, existiendo una compleja jerarquización de estas divinidades, muchas de ellas emparentadas entre sí. Los wamanis más poderosos eran por lo general las de mayor altitud y las que tenían mayor visualización desde lugares más alejados. Desde antes del Periodo Intermedio Tardío se edificaron centros ceremoniales relacionados con el culto a estos apus wamanis, los que para la época Inca son conocidos con el nombre de ushnus. Los Incas también edificaron por todo el imperio numerosos templos del 
sol, emplazados en lugares elevados, desde donde se tenía una vista privilegiada de todo el paisaje circundante, siendo los relacionados con el culto a la puesta del sol ubicados sobre complicados y elevados farallones rocosos, como se observa en Huarco (Cañete), Salitre (Mala) o Cerro La Horca (Paramonga), orientados hacia el litoral.

Antes de la llegada del Tawantinsuyu a la Costa Central peruana, las sociedades locales tenían sus divinidades a las cuales rendían un culto dirigido por un personal jerárquico especializado. Hasta el momento no se han identificado cuales, y donde estaban ubicados estos santuarios dedicados a las divinidades del valle de Huaura, con excepción del templo de Choque Ispana (Medina; 1650) ubicado al sur de la ciudad de Huacho (Ruiz 2006), el cual era objeto de culto tanto de pobladores costeños como de serranos; al igual como la huaca de Carquin, donde residía la huaca del dios Con (Medina; 1650). Una divinidad andina por lo general tenía un santuario principal y otros secundarios. Entonces la interrogante es ¿Dónde se ubicaban los santuarios de otros dioses del valle de Huaura, como Mamacocha, Urpiwachak o Vichama? Hasta este momento, los arqueólogos que venimos investigando este valle no hemos atendido esta interrogante.

La distribución espacial y sobre todo los materiales asociados que hemos identificado durante las excavaciones en el sector A de Cerro Colorado demuestran que se trata de un asentamiento de función ceremonial, no militar. La ubicación, por encima del nivel de la extensa área funeraria de Cerro Colorado (sector C), le otorga una connotación ceremonial, como ente protector encargado de regular las relaciones entre los vivos y los muertos. Pues, los contextos funerarios analizados del sector $\mathrm{C}$ evidenciaron un alto índice de ritualidad y sacralidad en las prácticas funerarias, que involucraban el proceso de enfardelamiento, el tratamiento corporal y los materiales asociados (van Dalen, Altamirano y Majchrzak 2018). Planteamos que se trata de un templo al mar (Mamacocha y Urpiwachak), entidad importante por ser dispensa alimenticia de la población local y ente encargada de capturar al sol en su poniente; pues en el cementerio de Cerro Colorado identificamos alrededor de 100 fardos de pescadores, como se puede juzgar a base de sus marcas del estrés laboral. Este culto abarcaba otros aspectos relacionados con el agua, como el río Huaura que drena sus aguas al litoral, los canales de irrigación que trasladan sus aguas para irrigar los terrenos agrícolas y las invocaciones para que se intensifiquen o detengan las lluvias (ritual desarrollado hasta la actualidad en las comunidades altoandinas utilizando agua de mar e invocando a los wamanis). Estamos de acuerdo con Brown (2015) que en estos lugares sagrados se desarrollaban también actividades de curación de enfermedades, proceso en el que intervenían necesariamente las divinidades locales.

Los muros concéntricos están restringiendo el acceso al área superior, donde se desarrollaba el culto a esta divinidad, a la vez que separaba los niveles estructurales que separaban lo sagrado (interno) de lo profano (externo), debiendo 
ingresar a cada nivel luego de cumplir ciertas ceremonias. Por ello se han encontrado ofrendas importantes, como el costal conteniendo hojas de coca, ubicado en la unidad 8, asociado al acceso del Muro Perimétrico 3, al igual que la ofrenda de una llama sacrificada.

Estas ofrendas asociadas a los muros perimétricos, no corresponden a ofrendas pre-constructivas, pues fueron depositadas cuando ya el muro estaba edificado y en funcionamiento. No se ha encontrado en las cercanías ni en asociación a estos muros recintos de función doméstica ni tampoco áreas domésticas de uso perenne, solo eventuales.

El hallazgo de otros materiales de función doméstica (instrumentos de molienda), así como huesos de animales (camélidos) y lentes de ceniza están revelando que estas ofrendas se realizaban en estadías temporales a la zona, en las cuales se preparaban alimentos, los cuales formaban parte de los ritos. Los alimentos preparados por los mismos pobladores in situ, formaban parte de los banquetes para las divinidades, siendo consumidas también por los visitantes. Los materiales culturales recuperados indican que esta área fue ocupada en el Intermedio Tardío (cultura Chancay), no se halló en las excavaciones ningún indicador que permita inferir que estos muros fueron construidos en el Horizonte Temprano o Intermedio Temprano. Las excavaciones y estratigrafía demostraron que todos estos muros fueron edificados durante el Periodo intermedio Tardío (cultura Chancay).

\section{Conclusiones}

En el presente artículo hemos presentado detalladamente el proceso de excavación realizado en el sector A del complejo arqueológico de Cerro Colorado, conformado por un cerro con tres muros perimétricos concéntricos. Las características de estos muros no son uniformes, pues durante su extensión varían en cuanto a dimensiones, materiales y técnicas constructivas. La funcionalidad que tuvo este sitio fue ceremonial, no hemos identificado indicadores que permitan suponer que tuvo alguna función militar o defensiva, como lo han venido planteando otros investigadores. Los materiales y contextos arqueológicos que hemos recuperado indican el desarrollo de actividades rituales y domésticas al interior de este sitio; cabe considerar la cercanía al área funeraria más extensa de la Costa Central Peruana, donde se encuentran enterrados miles de individuos de la cultura Chancay.

\section{Reconocimientos}

Un especial reconocimiento a los arqueólogos que participaron: Bach. Hans Grados Rodríguez (jefe de campo), Bach. Angélica López Carhuas, Bach. Carina Paullo Mendoza, Bach. Héctor Tenorio Carhuas, Bach. Hamilton Obregón Pillaca (asistentes de campo); Bach. Yesenia Huashuayo Casavilva, Lic. Lukas Simba 
Markshaj, Piero Muro Ipensa (practicantes de campo); Dr. Alfredo Altamirano Enciso (análisis material óseo), Bach. Miller Malpartida Gamarra, Bach. Jackeline Romero Rodríguez, Bach. Hamilton Obregón Pillaca (asistentes de gabinete); Decy Huamán Torres y Karen Carrión Barrionuevo (practicantes de gabinete). Así mismo, un reconocimiento a los pobladores de las Asociaciones Ollanta Humala, 9 de setiembre, Cerro Colorado II Etapa, Los Ángeles y Sol y Mar, quienes trabajaron en las excavaciones. A los señores Mauro Quispe Gervasio, Nilder Castillo Ríos, Wilmer Vega Jara y Teodoro Cayo Inocente, grandes dirigentes huachanos que gestionaron e hicieron posible la ejecución de la presente investigación, proyectando el desarrollo para su región.

\section{Referencias citadas}

BROWN VEGA, Margaret

2009 Prehispanic warfare during the Early Horizon and Late Intermediate period in the Huaura Valley, Peru. Current Anthropology 50 (2): 255266.

2010 Regional patterns of fortification and single forts: Evaluating the articulation of regional sociopolitical dynamics with localized phenomena. Comparative perspectives on the Archaeology of Coastal South America: 169-189. Eds. Cutright, R., Hurtado López, E., and A. Martin. Pittsburgh: Center for Comparative Archaeology, University of Pittsburgh; Lima: Fondo Editorial, Pontificia Universidad Católica del Perú; Quito: Ministerio de Cultura del Ecuador. Pitsburg.

2015 Weaving Together Evil Airs, Sacred Mountaintops, and War. Tracing the Relational: Theorizing Relationships Between Worlds, Spirits, and Temporalities: 276-316. University of Utah Press.

BROWN VEGA, Margaret; CRAIG, Nathan y ASENCIOS LINDO, Gerbert

2011 Ground truthing of remotely identified fortifications on the Central Coast of Peru. Journal of Archaeological Science, 38 (7): 16801689.

BROWN VEGA, Margaret; CRAIG, Nathan; CULLETON, Brendan; KENNETT, Douglas y ASENCIOS LINDO, Gerbert

2013 AMS radiocarbon dates from prehispanic fortifications in the Huaura valley, central coast of Perú. Radiocarbon, 55 (1): 1-12. Arizona.

BUENO MENDOZA, Alberto

2012 Antecedentes arqueológicos del Precerámico y el Horizonte Medio en el valle de Huaura. Kullpi. Investigaciones culturales en la provincia de Huaral y el Norte Chico, 6: 119-138. Pieter van Dalen, editor. Lima. 
ELIADE, Mircea

$2000 \quad$ Tratado de historia de las religiones. Morfología y dialéctica de lo sagrado. Madrid: Ediciones Cristiandad.

ESPINOSA SORIANO, Valdemar

1997 Los Incas. Economía, sociedad y estado en la era del Tahuantinsuyo. Ed. Amaru. Lima.

2014 "Etnia Quinua (hoy Huamanga)". Investigaciones Sociales. Revista del Instituto de Investigaciones Histórico Sociales, 33: 53-86. Facultad de Ciencias Sociales. Universidad Nacional Mayor de San Marcos. Lima.

GHEZZI, Iván y Clive RUGGLES

2006 Las trece torres de Chankillo: Arqueoastronomía y organización social en el primer observatorio solar de América. Boletín de Arqueología PUCP, 10: 215-236. Lima: Pontificia Universidad Católica del Perú.

2007 La naturaleza de la guerra prehispánica temprana: La perspectiva desde Chankillo. Revista Andina, 44: 199-225. Cusco.

GUTIÉRREZ, José y Patricia SUÁREZ MANJÓN

2007 Castillos y fortalezas feudales en Asturias: Metodología para su estu-

KAJZER, Leszek dio. Territorio, sociedad y poder, 2 . Madrid.

1993 Zamki i społeczeństwo. Przemiany architektury i budownictwa obronnego w Polsce w X-XVIII wieku. Wydawnictwo Uniwersytetu Łódzkiego, Łódz.

KRZANOWSKI, Andrzej

2008 Kultura Chancay. Srodkowe wybrzezé Perú. Instytut Amerykanistyki i studiów Polonijnych. Uniwersytetu Jagiellonskiego. Krakow, 225 Pp.

2016 Sitios amurallados o fortalezas Chancay en la costa central del Perú. Ensayos sobre arqueología y etnología de los Andes Peruanos: 183208. Jagiellonian University Press. Krakow.

MEDINA, Felipe de

$1650 \quad$ Relación del Lic. Felipe Medina visitador general de las idolatrías. Colección de libros y documentos referentes a la historia del Perú. Tomo III. Lima.

MORALES CAUTI, Héctor

2009 Informe final del Proyecto de rescate Arqueológico Complementario en la Parcela 3, sitio arqueológico de Cerro Colorado, Áreas Ocupadas II, III, IV y V, Asociaciones de Vivienda Palmeras Unidas y Cerro Colorado, distrito de Santa María, Provincia de Huaura. Presentado al Instituto Nacional de Cultura. 
MORALES CHOCANO, Daniel

1998 Compendio histórico del Perú. Del Paleolítico al Imperio Inca. Tomo

I. Lima: Ed. Milla Batres.

POZORSKI, Thomas

1987 Chavín, the early Horizon and the initial period. The origins and development of the Andean State: 36-46. J. Haas, S.G. Pozorski y T. Pozorski, editors. Cambridge: University Press Cambridge.

PROULX, Donald

1973 Archaeological investigations in the Nepeña valley, Perú. Research Report, 13. University of Massachusetts.

1985 Analysis of the early cultural sequence of the Nepeña valley, Perú". Research Report, 25. University of Massachusetts.

RODRIGUEZ GUILLÉN, Luis

2007 Informe final del Proyecto de Rescate Arqueológico en la Parcela 3 del sitio Cerro Colorado - Huacho. Informe final presentado al Instituto Nacional de Cultura.

ROSTWOROWSKI, María

1973 Urpayhuachac y el símbolo del mar. Boletín de Arqueología PUC, Boletín del Seminartio de Arqueología, 14: 13-22. Pontificie Universidad Católica. Lima.

2005 Recursos naturales renovables y pesca, siglos XVI - XVII. Instituto de Estudios Peruanos. Lima.

RUIZ ESTRADA, Arturo

1991 El entierro de un músico prehispánico de Huacho. Estudios sobre la cultura Chancay - Perú: 133-154. Andrzej Krzanowski, editor. Krakow.

2006 Exploraciones arqueológicas en la huaca Choque Ispana, valle de Huaura. Investigaciones Sociales, 16: 151-170. Instituto de Investigaciones Histórico Sociales, Universidad Nacional Mayor de San Marcos. Lima.

RUTHERFORD, Allen

2011 Mapeo del sitio Cerro Colorado en el valle de Huaura. Guara. Revista de investigación científica y cultural, 11: 12-24. Museo de Arqueología de la Universidad Nacional José Faustino Sánchez Carrión. Huacho.

2014 Fortaleza Cerro Colorado y su estructura política y económica del valle de Huaura en el periodo Intermedio tardío (1000-1476 d.C.). Guara. Revista de investigación científica y cultural, 18: 13-18. Museo de Arqueología de la Universidad Nacional José Faustino Sánchez Carrión. Huacho. 
TELLO, Julio C.

2004 La muralla de Santa. Arqueología y Sociedad, 15: 11-32. Museo de Arqueología y Antropología. Universidad Nacional Mayor de San Marcos. Lima.

2015 Cuadernos de Investigación del Archivo Tello. Arqueología del territorio Chancay, 11. Museo de Arqueología y Antropología, Universidad Nacional Mayor de San Marcos. Lima.

TOSSO MORALES, Walter

$2000 \quad$ Informe final del Proyecto de Estudio de Evaluación Arqueológica en la modalidad de evaluación, Prospección y Reconocimiento sistemático con excavaciones en el Asentamiento Humano Alberto Fujimori entregado al INC. Informe final presentado al Instituto Nacional de Cultura.

VALKENIER, Lisa

1995 New evidence for Chimu Capac and the early horizon period in the Supe valley, Peru. Journal of the steward anthropological society, Current research in Andean antiquity, 23 (1-2): 269-286. Urbana Champaign.

VALLEJO, Francisco

2010 Evidencias arqueológicas de un nuevo estilo cerámico en el valle de Huaura para el Periodo Intermedio tardío: El paso del Horizonte Medio al Intermedio Tardío. Arqueología en el Perú. Nuevos aportes para el estudio de las sociedades andinas: 229 -248.. Rubén Romero y Trine Pavel, editores. Lima.

VAN DALEN LUNA, Pieter

$2010 \quad$ Introducción al estudio arqueológico de Hualmay, valle de Huaura. Lima.

2011 El Tawantinsuyu en la costa norcentral peruana: valles de Chancay y Huaura. Investigaciones Sociales, 27: 77-104. Instituto de Investigaciones Histórico Sociales, Universidad Nacional Mayor de San Marcos. Lima.

2012a Análisis arquitectónico y secuencias de ocupación en el sitio de Pampa de Animas - La Wasa, Luriama, Campiña de Santa María, valle de Huaura. Kullpi. Investigaciones culturales en la provincia de Huaral y el Norte Chico, 6: 67-118. Lima.

2012b Investigaciones arqueológicas en el Castillo de Pasamayo: Un sitio amurallado Chancay en el valle bajo del río Chancay-Huaral. Arqueología y Sociedad, 24: 301-332. Museo de Arqueología y Antropología de San Marcos. Universidad Nacional Mayor de San Marcos. Lima.

2015 Julio C. Tello y las investigaciones arqueológicas en el territorio de la cultura Chancay. Cuadernos de Investigación del Archivo Tello, 11: 
9-21. Arqueología del territorio Chancay. Museo de Arqueología y Antropología, Universidad Nacional Mayor de San Marcos. Lima.

2016 Estrategias de dominación Tawantinsuyu en el complejo arqueologico de Lumbra, valle medio del río Chancay, provincia de Huaral. Tesis para optar el grado de Magister en Arqueología Andina. Universidad Nacional Mayor de San Marcos, Facultad de Ciencias Sociales. Lima.

2017a El hallazgo de un quipucamayoc en Cerro Colorado, Huacho. Arqueología y Sociedad, 31: 305-312. Museo de Arqueología y Antropología de San Marcos. Universidad Nacional Mayor de San Marcos. Lima.

2017b Sacachispa: un cementerio de agricultores de la cultura Chancay en Huando, Huaral. Lima.

VAN DALEN LUNA, Pieter; ALTAMIRANO ENCISO, Alfredo; y HUAMÁN CABANILLAS, Jesús

2013 Análisis del material arqueobotánico del sitio Pampa de las Ánimas, valle de Huaura, Perú, Temporada 2006. Investigaciones Sociales, 31: 39-64. Instituto de Investigaciones Histórico Sociales, Universidad Nacional Mayor de San Marcos. Lima.

VAN DALEN LUNA, Pieter; ALTAMIRANO ENCISO, Alfredo; GRADOS RODRÍGUEZ, Hans y CASTILLO VALLE, Rosario

2014 Los camélidos de Lumbra, valle medio del río Chancay, Perú. Investigaciones Sociales, 33: 87-104. Instituto de Investigaciones Histórico Sociales, Universidad Nacional Mayor de San Marcos. Lima.

VAN DALEN LUNA, Pieter; ALTAMIRANO ENCISO, Alfredo; MAJCHRZAK, Łukasz

2018 Marcas para la vida, señales para la muerte. Los cuerpos tatuados de la cultura Chancay en Cerro Colorado, Huacho, Perú. Revista M. Estudos sobre a morte, os mortos e o morrer, 3 (6): 344-377. Universidad de Rio de Janeiro. Rio de Janeiro.

VAN DALEN LUNA, Pieter; ALTAMIRANO ESPINOZA, Rosa

2018 Investigaciones arqueológicas y revalorización cultural del complejo arqueológico de Cerro Colorado, Huacho. Actas del III Congreso Nacional de Arqueología: 13-28. Ministerio de Cultura, Volumen I. Lima.

VAN DALEN LUNA, Pieter; CARBONEL ARANA, Dayanna

2015 Un caso de cordoma óseo (cáncer) en individuo Chancay de Cerro Colorado, Santa María, Huaura. Arqueología y Sociedad, 29: 167-182. Museo de Arqueología y Antropología de San Marcos. Universidad Nacional Mayor de San Marcos. Lima.

VAN DALEN LUNA, Pieter; TELLO CUADROS, Roberto; GRADOS RODRIGUEZ, Hans 
2015 Un Contexto funerario del Horizonte Medio procedente de Cerro Colorado, Huacho. Arqueología y Sociedad, 30: 407-424. Museo de Arqueología y Antropología de San Marcos. Universidad Nacional Mayor de San Marcos. Lima.

VAN DALEN LUNA, Pieter; GRADOS RODRIGUEZ, Hans; TELLO CUADROS, Roberto; VIVANCO, Iván; FLORES LIVIA, Wendy; y MARCELO GONZÁLES, Yerovi

2014 Resultados del proyecto de rescate arqueológico en el área de la parcela 4 y 5 del sitio arqueológico Cerro Colorado, Santa María, provincia de Huaura. Kullpi. Investigaciones culturales en la provincia de Huaral y el Norte Chico, 7: 189-216. Lima.

VILLAR CORDOVA, Pedro

1982 [1935] Arqueología del departamento de Lima. Segunda Edición. Lima: Ed. Atusparia.

WILLEY, Gordon

1953 Prehistoric settlements patterns in the Virú Valley, Perú. Bureau of American Ethnology Bulletin, 155, Washington D.C.: Smithsonian Institute Press.

WILSON, David

1988 Prehistoric Settlement patterns in the lower Santa Valley, Perú: A regional perspective on the origins and development of complex North Coast Society. Washington D.C.: Smithsonian Institution Press.

1997 Early state formation on the North Coast of Perú: A critique of the city state model. The archaeology of city states: Cross cultural approaches: 229-244. Washington D.C.: Smithsonian Institution Press. 